\title{
Flow cytometry for intracellular SPION quantification: specificity and sensitivity in comparison with spectroscopic methods
}

This article was published in the following Dove Press journal:

International Journal of Nanomedicine

26 June 2015

Number of times this article has been viewed

\author{
Ralf P Friedrich,' Christina \\ Janko,' Marina Poettler,' \\ Philipp Tripal,' Jan Zaloga,' \\ Iwona Cicha,' Stephan \\ Dürr, ${ }^{1,2}$ Johannes Nowak, ${ }^{3}$ \\ Stefan Odenbach, ${ }^{3}$ loana \\ Slabu, ${ }^{4}$ Maik Liebl, ${ }^{4}$ Lutz \\ Trahms, ${ }^{4}$ Marcus Stapf, ${ }^{5}$ \\ Ingrid Hilger, ${ }^{5}$ Stefan Lyer, \\ Christoph Alexiou' \\ 'Department of Otorhinolaryngology, \\ Head and Neck Surgery, Section \\ of Experimental Oncology \\ and Nanomedicine, University \\ hospital Erlangen, ${ }^{2}$ Department \\ of Otorhinolaryngology, Head and \\ Neck Surgery, Section of Phoniatrics \\ and Pediatric Audiology, University \\ hospital Erlangen, Erlangen, \\ ${ }^{3}$ Technische Universität Dresden, \\ Chair of Magnetofluiddynamics, \\ Measuring and Automation Technology, \\ Dresden, ${ }^{4}$ Physikalisch-Technische \\ Bundesanstalt Berlin, Berlin, \\ ${ }^{5}$ Department of Radiology, Division \\ of Diagnostic and Interventional \\ Radiology, Experimental Radiology, \\ University hospital Jena, Jena, Germany
}

Correspondence: Christoph Alexiou Department of Otorhinolaryngology, Head and Neck Surgery, Section of Experimental Oncology and Nanomedicine, Else Krüner-FreseniusStiftung-Professorship, University hospital Erlangen, Glückstrasse 10a, 91054

Erlangen, Germany

Tel +499|3 I8534769

Fax +499|3 I8534828

Email c.alexiou@web.de
Abstract: Due to their special physicochemical properties, iron nanoparticles offer new promising possibilities for biomedical applications. For bench to bedside translation of superparamagnetic iron oxide nanoparticles (SPIONs), safety issues have to be comprehensively clarified. To understand concentration-dependent nanoparticle-mediated toxicity, the exact quantification of intracellular SPIONs by reliable methods is of great importance. In the present study, we compared three different SPION quantification methods (ultraviolet spectrophotometry, magnetic particle spectroscopy, atomic adsorption spectroscopy) and discussed the shortcomings and advantages of each method. Moreover, we used those results to evaluate the possibility to use flow cytometric technique to determine the cellular SPION content. For this purpose, we correlated the side scatter data received from flow cytometry with the actual cellular SPION amount. We showed that flow cytometry provides a rapid and reliable method to assess the cellular SPION content. Our data also demonstrate that internalization of iron oxide nanoparticles in human umbilical vein endothelial cells is strongly dependent to the SPION type and results in a dose-dependent increase of toxicity. Thus, treatment with lauric acidcoated SPIONs $\left(\mathrm{SEON}^{\mathrm{LA}}\right)$ resulted in a significant increase in the intensity of side scatter and toxicity, whereas SEON ${ }^{\mathrm{LA}}$ with an additional protein corona formed by bovine serum albumin (SEON ${ }^{\text {LA-BSA }}$ ) and commercially available Rienso ${ }^{\circledR}$ particles showed only a minimal increase in both side scatter intensity and cellular toxicity. The increase in side scatter was in accordance with the measurements for SPION content by the atomic adsorption spectroscopy reference method. In summary, our data show that flow cytometry analysis can be used for estimation of uptake of SPIONs by mammalian cells and provides a fast tool for scientists to evaluate the safety of nanoparticle products.

Keywords: low cytometry, side scatter, intracellular superparamagnetic iron oxide nanoparticles, quantification, spectroscopy

\section{Introduction}

Superparamagnetic iron oxide nanoparticles (SPIONs) are becoming increasingly important for various applications in technology and medicine. They are particularly useful for many diagnostic applications, such as T2-weighted magnetic resonance imaging of the lymph nodes, liver, intestines, and cardiovascular system, as well as for the treatment of anemia. ${ }^{1-3}$ Consequently, these nanoparticles will not only be released into the environment, but will also inevitably come in contact with the human body. ${ }^{4-6}$ In order to reliably estimate the possible effects of SPIONs on living organisms, it is crucial to find appropriate models to determine the toxicity and biocompatibility of these particles. In vitro models are reliable tools to investigate their effects on cells. Apart from their physicochemical properties, the internalization and/or binding of 
nanoparticles to cells is an important determinant of nanoparticle toxicity.

Several existing techniques, including transmission electron microscopy (TEM), cryogenic TEM, confocal microscopy, and fluorescence microscopy, are able to visualize the localization of particles within cells and enable us to understand the internalization process and track the fate of nanoparticles within cells. ${ }^{7-9}$ Although these methods are appropriate to detect single particles or particle agglomerates, their drawback is the lack of ability to efficiently quantify the amount of particles within a sample of several hundred thousand cells, which is required for a reliable quantification.

At present, several methods of SPION quantification are in use, including ultraviolet spectrophotometry (UVS), magnetic particle spectroscopy (MPS), and atomic adsorption spectroscopy (AAS). ${ }^{10-13}$ However, those methods are timeconsuming, and in case of MPS and AAS, cost-intensive. Hence, a method that offers simultaneous measurement of the cellular nanoparticle content and a rapid estimation of nanoparticle toxicity would be of great benefit. Flow cytometry is a promising technique that might fulfill these demands. This method allows simultaneous determination of multiple parameters, so that information about cell number, size, granularity, markers of cellular apoptosis and necrosis, plasma membrane integrity, membrane potential, and DNA content can be collected in parallel. ${ }^{14,15}$ Moreover, previous reports have shown a correlation between flow cytometric side scatter data and increasing cellular amounts of metal and metal oxide nanoparticles. ${ }^{16-19}$ Also, the parallel readout of additional parameters (production of reactive oxygen species, DNA damage) has already been reported. ${ }^{19}$ Thus, this approach can be very useful to simultaneously assess the direct relationship between nanoparticle uptake and cellular toxicity. However, no trials to determine the absolute cellular amount of different SPION types have been performed by this method so far.

We therefore evaluated the possibility of using flow cytometric side scatter data to quantify the cellular SPIONload in primary human endothelial cells. For that purpose, we investigated three types of iron oxide nanoparticles with different physicochemical properties and different coating, which are likely to affect cellular uptake. We found a good correlation between cellular SPION amounts, as quantified by established methods (UVS, MPS, and AAS), and the side scatter data, which provides evidence that use of flow cytometry is not only suitable for toxicity studies, but also offers a reliable method to simultaneously determine the cellular SPION content.

\section{Materials and methods Nanoparticles}

Lauric acid (LA)-coated SPIONs (SEON ${ }^{\mathrm{LA}}$ ) and lauric acid/albumin hybrid-coated SPIONs (SEON ${ }^{\text {LA-BSA }}$ ) were synthesized at the Section of Experimental Oncology and Nanomedicine (SEON), University Hospital Erlangen, as previously described. ${ }^{20}$ In brief, SEON ${ }^{\mathrm{LA}}$ were synthesized by coprecipitation of iron (III) chloride and iron (II) chloride under an argon atmosphere in alkaline medium and subsequent in situ coating with lauric acid. To produce $\mathrm{SEON}^{\mathrm{LA}-\mathrm{BSA}}$, SEON ${ }^{\mathrm{LA}}$ particles were added to a freshly prepared $20 \%$ bovine serum albumin solution and incubated for 30 minutes under constant stirring. After purification and concentration by centrifugal ultrafiltration (molecular weight cut-off $100 \mathrm{kDa}$; KrosFlo ${ }^{\circledR}$ Research IIi tangential flow filtration system, Spectrum Laboratories, Rancho Dominguez, CA, USA) the particles were sterilized by filtration through a $0.22 \mu \mathrm{m}$ membrane filter. SPION stock concentrations were $4.19 \mu \mathrm{g}_{\mathrm{Fe}} / \mathrm{mL}$ for SEON ${ }^{\mathrm{LA}-\mathrm{BSA}}$ and $9.49 \mu \mathrm{g}_{\mathrm{Fe}} / \mathrm{mL}$ for SEON ${ }^{\mathrm{LA}}$. Rienso ${ }^{\circledR}$ (Ferumoxytol, $30 \mu \mathrm{g}_{\mathrm{Fe}} / \mathrm{mL}$; superparamagnetic iron (III)-oxide cores coated with a small-sized carbohydrate shell of polyglucose sorbitol carboxymethylether [PSC]) was purchased from Takeda, London, UK. SPION concentrations used in the text always refer to the iron content and were specified either as $\mu \mathrm{g}_{\mathrm{Fe}} / \mathrm{mL}$ medium or cell lysate, $\mu \mathrm{g}_{\mathrm{Fe}} / \mathrm{cm}^{2}$ plate surface or $\mathrm{pg}_{\mathrm{Fe}} / \mathrm{cell}$.

\section{Characterization of SPIONs}

For TEM, samples were prepared by adding $25 \mu \mathrm{L}$ of diluted SPION solution (final iron concentration $25 \mu \mathrm{g}_{\mathrm{Fe}} / \mathrm{mL}$ ) on top of a copper grid. Samples were imaged by TEM (Philips CM 300 UT, Eindhoven, the Netherlands) at an acceleration voltage of $300 \mathrm{kV}$. Particle core size was measured from transmission electron micrographs using ImageJ image processing software (National Institutes of Health, Bethesda, MD, USA).

For Fourier transform infrared (FTIR) analysis, $3 \mathrm{~mL}$ of the respective SPION suspension were frozen in a $-80^{\circ} \mathrm{C}$ freezer and then freeze-dried overnight. FTIR spectra of the lyophilized samples were recorded with a Bruker Alpha FTIR spectrometer operated in attenuated total reflection mode from $4,000 \mathrm{~cm}^{-1}$ to $400 \mathrm{~cm}^{-1}$ with a step size of $0.5 \mathrm{~cm}^{-1}$.

Hydrodynamic sizes and zeta potentials of the nanoparticle aggregates were determined with a Zetasizer Nano ZS (Malvern Instruments, Malvern, UK). The respective SPION suspensions were diluted to a final total iron concentration of $25 \mu \mathrm{g}_{\mathrm{Fe}} / \mathrm{mL}$. As dispersants, either cell culture medium (Roswell Park Memorial Institute 1640, Life Technologies, Darmstadt, Germany) or Millipore water were used. 
Size measurements were performed in triplicate and zeta potential measurements in hexaplicate.

Stability of the nanoparticles in complex physiological fluids was evaluated using cell culture medium (Endothelial Cell Growth Medium, PELOBiotech, Planegg, Germany) or sheep blood obtained from Fiebig-Nährstofftechnik (Idstein Niederauroff, Germany). Sheep blood was anticoagulated with ethylenediaminetetraacetic acid at a concentration of $1.5 \mathrm{mg} / \mathrm{mL} .{ }^{21}$ To gain information about possible agglomeration of nanoparticles caused by media or sheep blood, the fluids were mixed with SPIONs $\left(2.62 \mathrm{mg}_{\mathrm{Fe}} / \mathrm{mL} \mathrm{H}_{2} \mathrm{O}\right)$ at a 2:1 ratio. The presence of agglomerates was subsequently determined macroscopically and microscopically using a digital camera and an optical bright-field microscope, respectively.

\section{Cell culture and sample preparation}

Primary human umbilical vein endothelial cells (HUVECs) were purchased from PromoCell (Heidelberg, Germany). In all experiments, HUVECs pooled from four donors were used at passage 3-5, which corresponds to 12-20 cell divisions. HUVECs were cultivated without antibiotics in enhanced Endothelial Cell Growth Medium from PELOBiotech at $37^{\circ} \mathrm{C}$ and $5.0 \% \mathrm{CO}_{2}$. For further passaging, trypsinization was performed using the Subculture Reagent kit from PELOBiotech according to the manufacturer's instructions.

For experiments, $3.2 \times 10^{5}$ HUVECs were seeded into $25 \mathrm{~cm}^{2}$ cell culture plates. After 24 hours, SPIONs (SEON ${ }^{\mathrm{LA}}$, SEON $^{\text {LA-BSA }}$, and Rienso ${ }^{\circledR}$ ) were added to a final concentration of $0,10,20,30,40,50$, and $100 \mu \mathrm{g}_{\mathrm{Fe}} / \mathrm{mL}$ cell culture medium, which corresponds to a $0,2.4,4.8,7.2,9.6,12$, and $24 \mu \mathrm{g}_{\mathrm{Fe}} / \mathrm{cm}^{2}$ cell culture plate area. Thus, the correlation between the SPION concentration in cell culture medium and on the plate surface area was kept constant for all experiments. Cells were incubated with SPIONs for another 48 hours, followed by harvesting. The cell pellets were resuspended in $1 \mathrm{~mL}$ of phosphate-buffered saline. Cell suspensions were used to determine the absolute cell counts and viability with the MUSE ${ }^{\circledR}$ cell analyzer (Merck-Millipore, Billerica, MA, USA), as well as for flow cytometry analysis. Remaining cells were subsequently used for SPION quantification measurements using UVS, MPS, or AAS techniques.

\section{Quantification of SPIONs in cell lysates}

Defined cell numbers $\left(4 \times 10^{5}\right)$ were collected by centrifugation $\left(5\right.$ minutes, $1,000 \mathrm{~g}, 4^{\circ} \mathrm{C}$ ). The cell pellet was lysed with $100 \mu \mathrm{L}$ of $10 \%$ sodium dodecyl sulfate (Roth,
Karlsruhe, Germany) and stored at $-20^{\circ} \mathrm{C}$ until further use. After thawing, the cell lysates were agitated (1,400 rpm) for 5 minutes at $95^{\circ} \mathrm{C}$ and immediately vortexed at high power to crop genomic DNA. Afterward, the cell lysates were incubated for 1 hour in an ultrasonic bath to ensure a homogeneous suspension of the SPIONs within the cell lysate. SPION standards $(0,0.5,1.0,1.5,2.0,5.0,10,15,20$, and $50 \mu \mathrm{g}_{\mathrm{Fe}} / \mathrm{mL}$ ) were prepared in $10 \%$ sodium dodecyl sulfate and in untreated cell lysate solutions.

\section{Ultraviolet spectrophotometry}

The UVS quantification of the SPION amount was modified after Dadashzadeh et al and performed by measuring the optical density at $370 \mathrm{~nm}\left(\mathrm{OD}_{370}\right){ }^{22}$ In detail, $50 \mu \mathrm{L}$ of cell lysate $\left(2 \times 10^{5}\right.$ cells $)$ and SPION standards were pipetted into 96-well plates (Techno Plastic Products AG, Trasadingen, Switzerland) and the $\mathrm{OD}_{370}$ was measured in a spectrophotometer (FilterMax F5, Molecular Devices, Sunnyvale, CA, USA). Standard dilutions of SPIONs enabled an absolute quantification of the iron nanoparticle concentration in the cell lysates. As the amount of cells was quantified before cell lysis, the SPION concentration was subsequently normalized to the cell number.

\section{Magnetic particle spectroscopy}

The amount of SPIONs accumulated in the cells was determined with MPS. The method is based on the nonlinear part of the magnetic susceptibility response of magnetic nanoparticles to an oscillating magnetic field. As a result, MPS is a sensitive detection method that allows quantification of the magnetic nanoparticle iron content without being affected by cells or suspension medium. For MPS quantification, $25 \mu \mathrm{L}$ of cell lysate $\left(1 \times 10^{5}\right.$ cells $)$ were pipetted in MicroAmp fast reaction tubes (Life Technologies) and analyzed by MPS (MP-Spectrometer, Bruker, Germany).

\section{Atomic absorption spectroscopy}

The absolute iron content was determined by flame AAS using an AAS 5 FL spectrometer (Analytik Jena AG, Germany). Before measurement, $25 \mu \mathrm{L}$ cell lysate $\left(1 \times 10^{5}\right.$ cells) samples were incubated for 24 hours with $32 \% \mathrm{HCl}$ (v/v, extra pure, Carl Roth GmbH, Germany) and mixed roughly multiple times to allow complete sample dissociation. To remove proteins possibly interfering with the iron determination, a protein precipitation step using $10 \%$ trichloroacetic acid (w/v, Carl Roth $\mathrm{GmbH}$ ) was performed, followed by centrifugation at $3,600 \mathrm{~g}$ for 5 minutes. The resulting supernatant was transferred to a new vial and used 
for iron measurements. For calibration of the device and later quantification of the sample's iron content, a calibration curve was prepared with defined iron concentrations ranging from 0 to $50 \mu \mathrm{mol}_{\mathrm{Fe}} / \mathrm{L}$. If the iron concentration measured in a sample exceeded the range of the prepared calibration curve, the sample was diluted using double-distilled $\mathrm{H}_{2} \mathrm{O}$ and remeasured.

\section{Analysis of HUVECs using flow cytometry}

Flow cytometry was performed using a Gallios cytofluorometer (Beckman Coulter, Fullerton, CA, USA) in order to analyze cell morphology (forward scatter and side scatter), cell viability, and in particular to quantify the cellular SPION content. For cell death analysis, $50 \mu \mathrm{L}$ aliquots of cell suspension were incubated with $250 \mu \mathrm{L}$ of freshly prepared staining solution containing $1 \mu \mathrm{g} / \mathrm{mL}$ Annexin V-fluorescein isothiocyanate, $1 \mu \mathrm{g} / \mathrm{mL}$ Hoechst 33342 ,

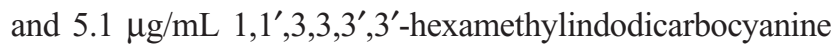
iodide [DiIC1(5)] (all from Life Technologies), and $20 \mu \mathrm{g} / \mathrm{mL}$ propidium iodide (Sigma-Aldrich, St. Louis, MO, USA) in Ringer's solution (Baxter Healthcare, Zurich, Switzerland) for 20 minutes at $4^{\circ} \mathrm{C} . .^{15}$

Side scatter was extracted from the flow cytometric measurements after gating on phenotypically healthy cells, characterized by Annexin V-negative and propidium iodidenegative staining. The side scatter values from the raw data of the untreated control cells was set to $100 \%$ and the side scatter increase of the nanoparticle-treated cells was calculated accordingly. Counting beads were not added into the vials to avoid unspecific binding to the cells and unspecific side scatter increases. Every sample was measured for a fixed time (60 seconds). Detected amounts of cells (events) were dependent on treatment of the cells due to reduced proliferation and cell death. Thus, flow cytometry provides relative cell counts (events).
For analysis of the cell cycle and DNA degradation, a further $200 \mu \mathrm{L}$ of the cell suspensions were fixed by adding $3 \mathrm{~mL}$ of $70 \%(\mathrm{v} / \mathrm{v})$ ice-cold ethanol and stored at $-20^{\circ} \mathrm{C}$ for further processing. The cells were then centrifuged ( 5 minutes, $1,000 \mathrm{~g}$, $4^{\circ} \mathrm{C}$ ), the supernatant was removed, and the cells were washed with phosphate-buffered saline once. The cells were resuspended in $0.5 \mathrm{~mL}$ of phosphate-buffered saline, and $0.5 \mathrm{~mL}$ of DNA extraction buffer (192 mL of $0.2 \mathrm{M} \mathrm{Na}_{2} \mathrm{HPO}_{4}, 8 \mathrm{~mL}$ $0.1 \%$ Triton $\mathrm{X}-100(\mathrm{v} / \mathrm{v}), \mathrm{pH} 7.8)$ was added and incubated for 5 minutes at room temperature. Cells were centrifuged ( 5 minutes, $1,000 \mathrm{~g}, 4^{\circ} \mathrm{C}$ ), the supernatant was removed, and the cells were resuspended in $1 \mathrm{~mL}$ of propidium iodide-Triton $\mathrm{X}$ DNA staining solution $(50 \mu \mathrm{g} / \mathrm{mL}$ propidium iodide in water and $1 \mathrm{mg} / \mathrm{mL}$ sodium citrate, $0.1 \%$ Triton X-100 (v/v)) and incubated for 30 minutes in the dark. ${ }^{23}$

Electronic compensation was used to eliminate bleed through fluorescence. The data analysis was performed with Kaluza software version 2.0 (Beckman Coulter). All flow cytometry analyses were conducted in three independent experiments, each with triplicate samples.

\section{Results}

\section{Characterization of SPIONs}

As the nanoparticle size can affect cellular uptake, we first determined the size distribution of the SPIONs using TEM. Interestingly, we found only minimal differences in the average size of single SEON cores (approximately $11 \mathrm{~nm}$ ), whereas cores of the Rienso ${ }^{\circledR}$ particles were significantly smaller (5.8 nm, Table 1; Figure S1A).

The chemical structures of all three samples were analyzed with FTIR (Table 1, Figure S1B). The Fe-O peak at $550 \mathrm{~cm}^{-1}$ was visible in all spectra. The spectra of SEON ${ }^{\mathrm{LA}}$ contained the distinctive peaks for the $\mathrm{C}-\mathrm{H}$ vibrations of lauric acid from $2,957 \mathrm{~cm}^{-1}$ to $2,844 \mathrm{~cm}^{-1}$ as well as the carbonyl group stretch vibration at $1,698 \mathrm{~cm}^{-1}$ which was

Table I Biophysical properties of superparamagnetic iron oxide nanoparticles

\begin{tabular}{llll}
\hline & SEON & SEON & Rienso $^{\circledR}$ \\
\hline Core diameter $(\mathrm{nm})$ & $\mathrm{II} .0 \pm 2.2$ & $10.8 \pm \mathrm{I} .8$ & $5.8 \pm 0.8$ \\
Hydrodynamic diameter $(\mathrm{nm})$ & $45 . \mathrm{I} \pm 0.7$ & $61.8 \pm \mathrm{I} .6$ & $30.8 \pm 0.1$ \\
Zeta potential in $\mathrm{H}_{2} \mathrm{O}(\mathrm{mV})$ & $-39.4 \pm 0.7$ & $-43.0 \pm 0.7$ & $-42.6 \pm 2.3$ \\
Zeta potential in media $(\mathrm{mV})$ & $-15.5 \pm 0.9$ & $-15.1 \pm \mathrm{I} .5$ & $-15.9 \pm 0.7$ \\
Biocompatibility in media & No & Yes & Yes \\
Biocompatibility in blood & No & Yes & Yes \\
FTIR vibration peaks $\left(\mathrm{cm}^{-1}\right)$ & Fe-O 550 C-H stretch 2,957- & Fe-O 550 C-H stretch 3,000-2,8I6 & Fe-O 550 C-H stretch 2,965- \\
& 2,854 free carbonyl stretch I,698 & carbonyl stretch I,647 O-H/N-H stretch & 2,800 carbonyl stretch I,590 O-H \\
& chemisorbed carbonyl stretch & $3,400-3,000$ carbonyl aminoester stretch & stretch 3,400-3,000 \\
\hline
\end{tabular}

Note: Summary of measured biophysical properties of SEON ${ }^{L A}$, SEON ${ }^{L A-B S A}$, and Rienso ${ }^{\circledR}$ particles.

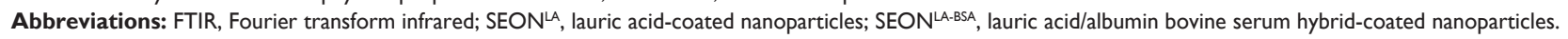


partially shifted to lower wavenumbers $\left(1,524 \mathrm{~cm}^{-1}\right)$, possibly due to chemisorption onto the particle surface. SEON ${ }^{\text {LA-BSA }}$ exhibited an infrared spectrum with rather broad -OH and - $\mathrm{NH}$ stretch vibration peaks above $3,000 \mathrm{~cm}^{-1}$ and dominant carbonyl and carbonyl aminoester peaks at $1,647 \mathrm{~cm}^{-1}$ and $1,516 \mathrm{~cm}^{-1}$, respectively. These results were consistent with previous findings. ${ }^{20}$ The spectrum of Rienso ${ }^{\circledR}$ showed typical broad C-H vibration $\left(2,965-2,800 \mathrm{~cm}^{-1}\right)$, -OH stretch vibration $\left(3,400-3,200 \mathrm{~cm}^{-1}\right)$ patterns and a distinct carbonyl peak at $1,590 \mathrm{~cm}^{-1}$, all most likely belonging to the PSC.

In distilled water, the hydrodynamic diameter of $45.1 \mathrm{~nm}$ $\left(\mathrm{SEON}^{\mathrm{LA}}\right), 61.8 \mathrm{~nm}\left(\mathrm{SEON}^{\mathrm{LA}-\mathrm{BSA}}\right)$, and $30.8 \mathrm{~nm}\left(\right.$ Rienso $\left.^{\circledR}\right)$ was determined (Table 1; Figure S1C), indicating that particle coating is the main factor determining the effective size of the investigated nanoparticles.

Determination of the zeta potential revealed similar strong negative surface charges of SEON ${ }^{\mathrm{LA}}$, SEON ${ }^{\mathrm{LA}-\mathrm{BSA}}$, and Rienso ${ }^{\circledR}$ in distilled water $(-39.4 \pm 0.74,-43.0 \pm 0.72$, and $-42.6 \pm 2.30 \mathrm{mV})$. However, upon dilution of SPIONs in cell culture medium, the surface charges of SEON ${ }^{\mathrm{LA}-\mathrm{BSA}}$, SEON $^{\mathrm{LA}}$, and Rienso ${ }^{\circledR}$ became significantly more positive $(-15.1 \pm 1.52,-15.5 \pm 0.85$, and $-15.9 \pm 0.71 \mathrm{mV})$ indicating the absorption of similar ionic substances from the dispersion medium (Table 1; Figure S1D).

The stability of the SPIONs was further investigated in cell culture medium. In contrast with SEON ${ }^{\mathrm{LA}-\mathrm{BSA}}$ and Rienso $^{\circledR}$, which showed no signs of aggregation, SEON ${ }^{\mathrm{LA}}$ rapidly produced distinct agglomerates (Table 1; Figure S1E). Similar results were achieved in ethylenediaminetetraacetic acid-stabilized blood at a macroscopic and microscopic level, where SPIONs conjugated with lauric acid (SEON $\left.{ }^{\mathrm{LA}}\right)$ were unstable and aggregated in a time-dependent manner (Table 1, Figure S1F and G). In contrast, nanoparticles additionally coated with serum albumin (SEON $\left.{ }^{\mathrm{LA}-\mathrm{BSA}}\right)$, as well as Rienso ${ }^{\circledR}$ particles, were stable and did not show any signs of agglomeration in blood (Table 1; Figure S1F and G). The biophysical properties suggest that SEON ${ }^{\mathrm{LA}-\mathrm{BSA}}$ and Rienso ${ }^{\circledR}$ are suitable for in vitro and in vivo applications, whereas $\mathrm{SEON}^{\mathrm{LA}}$ should be avoided due to a propensity to aggregate.

\section{Quantification of SPIONs by UVS, MPS, and AAS}

To quantify the cellular SPION content, we modified a photometric technique recently published by Dadashzadeh et al. ${ }^{22}$ Using this method, the absorption maximum for SPIONs should be observable at $370 \mathrm{~nm}$. To ensure that this also applies to the SPIONs used in this study, we prepared
SPION dilutions of $30 \mu \mathrm{g}_{\mathrm{Fe}} / \mathrm{mL}$ in $10 \%$ sodium dodecyl sulfate and monitored the corresponding absorption spectra between $200 \mathrm{~nm}$ and $900 \mathrm{~nm}$ with a stepwise increase of $2 \mathrm{~nm}$. Beside an obvious absorption maximum at $\sim 222 \mathrm{~nm}$, a second absorption peak is observable at a wavelength of roughly $\sim 370 \mathrm{~nm}$ (Figure S2A). To test this method for reproducibility and for medium-throughput suitability in 96-well format, we measured the absorption of $50 \mu \mathrm{L}$ dilutions of SPIONs $\left(0-50 \mu \mathrm{g}_{\mathrm{Fe}} / \mathrm{mL}\right)$ in $10 \%$ sodium dodecyl sulfate at $370 \mathrm{~nm}$ and found a direct correlation between absorption and concentration of the particles (Figure S2B-D). Another very important aspect for quantification of SPIONs within cell lysates by a photometric approach is that the absorption of cellular components should not interfere with the absorption peak of SPIONs at $370 \mathrm{~nm}$. Therefore, the reliability of the described method was verified by adding different SPION concentrations $\left(0-50 \mu \mathrm{g}_{\mathrm{Fe}} / \mathrm{mL}\right.$ iron) into HUVEC lysates (Figure 1A). Even in these settings, an almost perfect correlation was observed between the measured absorption and quantity of added SPIONs, demonstrating the high degree of consistency for determination of the SPION concentration in cell lysates with this method.

Similar SPION contents as found with the UVS method were measured using MPS. MPS is a suitable method for specific quantification of magnetic nanoparticles in biological samples. ${ }^{11}$ Correspondingly, the correlation between the magnetic moment and the SPION concentration was nearly perfect (Figures 1B and S2C). This was independent of the absence or presence of cell lysate within the standard solutions. Interestingly, the MPS detection threshold of $0.3 \mu \mathrm{g}_{\mathrm{Fe}} / \mathrm{mL}$ for SEON ${ }^{\mathrm{BSA}-\mathrm{LA}}$ and $0.5 \mu \mathrm{g}_{\mathrm{Fe}} / \mathrm{mL}$ for $\mathrm{SEON}^{\mathrm{LA}}$ was far beneath the UVS detection threshold of approximately $5 \mu \mathrm{g}_{\mathrm{Fe}} / \mathrm{mL}$ as defined by $3 \sigma$ criteria (Table $\mathrm{S} 1$ ). However, the MPS method was less sensitive to the Rienso ${ }^{\circledR}$ particles than to the other two types of SPIONs. Most likely this is related to the very small core particle size of Rienso ${ }^{\circledR}$ which resulted in a slightly higher detection threshold of $2.5 \mu \mathrm{g}_{\mathrm{Fe}} / \mathrm{mL}$ using the MPS technique.

AAS is another established method to determine the amount of elementary iron (Figures $1 \mathrm{C}$ and S2D). Using this technique, iron amount in cell lysates containing above $0.6 \mu \mathrm{g}_{\mathrm{Fe}} / \mathrm{mL} \mathrm{SEON}^{\mathrm{LA}}, \mathrm{SEON}{ }^{\mathrm{BSA}-\mathrm{LA}}$, or Rienso ${ }^{\circledR}$ particles, were reliably measured (Table S1). In contrast with the UVS and MPS methods, AAS quantifies the total iron content of a solution and not only iron-containing SPIONs. In consequence, this method is not dependent on the magnetic moment of nanoparticles, and can be used also for quantification of nanoparticles that exhibit a very low magnetic moment, like 
A

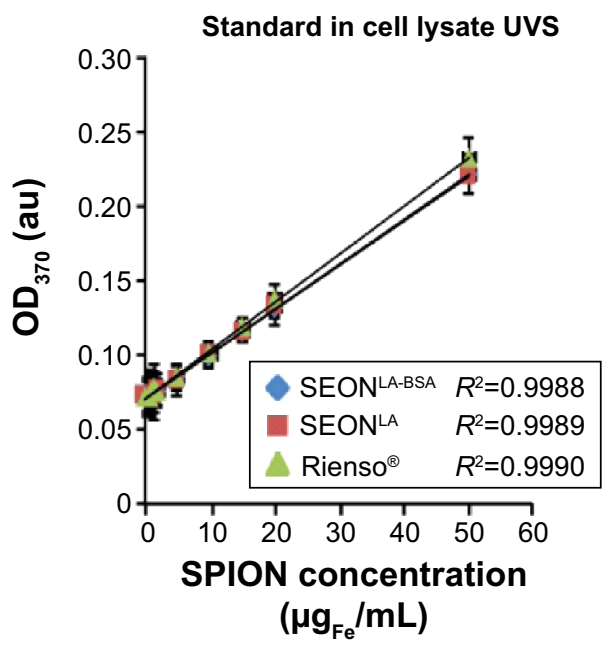

B

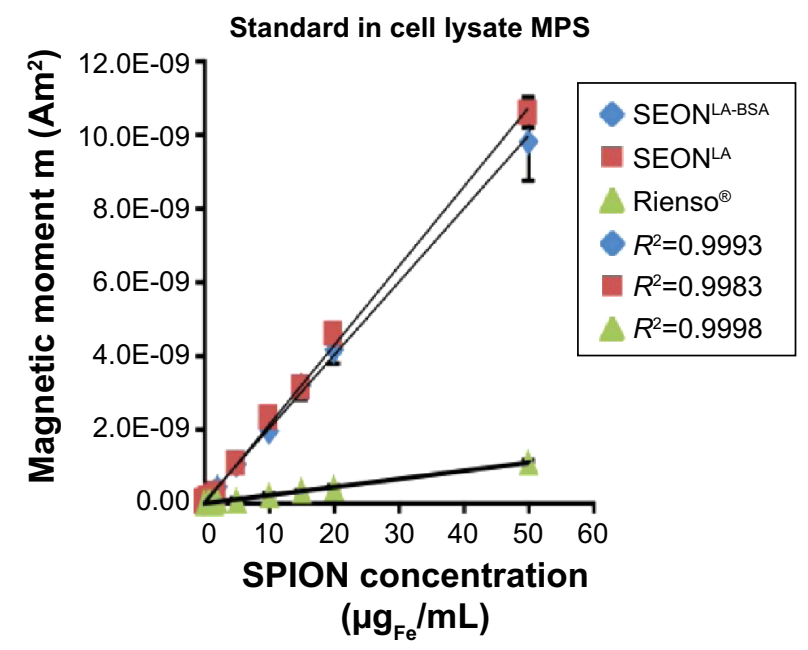

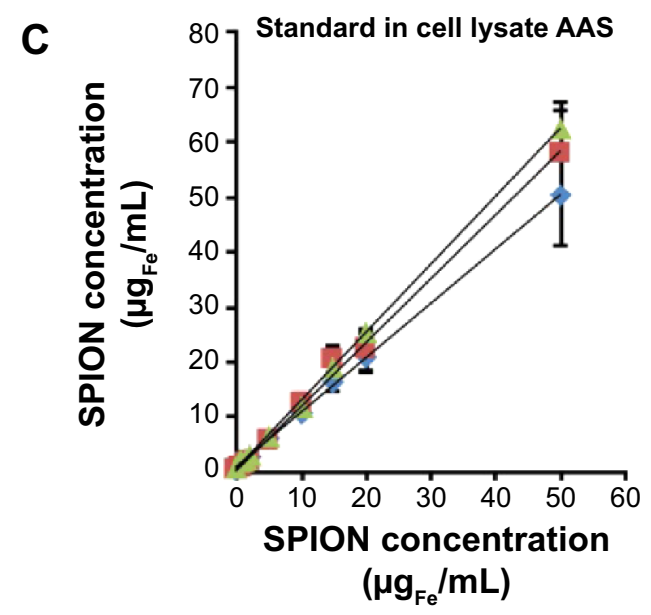

SEONLA-BSA
SEONLA
$\triangle$ Rienso $^{\circledR}$
$R^{2}=0.9997$
$R^{2}=0.9964$
$R^{2}=0.9994$

Figure I Suitability of UVS, MPS, and AAS techniques for measurement of SPION concentration in cell lysates.

Notes: (A) UVS measurements at $370 \mathrm{~nm}$, (B) MPS measurements, and (C) AAS measurements with increasing SPION concentration in cell lysates. Data are presented as the mean \pm standard deviation ( $\mathrm{n}=3$ with triplicates). $R^{2}$ represents the coefficient of determination.

Abbreviations: au, absorbance units; SPION, superparamagnetic iron oxide nanoparticle; UVS, ultraviolet spectrophotometry; MPS, magnetic particle spectroscopy; AAS, atomic adsorption spectroscopy; SEON ${ }^{L A}$, lauric acid-coated nanoparticles; SEON ${ }^{L A-B S A}$, lauric acid/albumin bovine serum hybrid-coated nanoparticles; $O D_{370}$, optical density at 370 nm.

the Rienso ${ }^{\circledR}$ particles. Moreover, compared with the UVS method, AAS is especially useful when particles must be quantified in solutions characterized by a high absorption around $370 \mathrm{~nm}$.

\section{Cellular uptake of SPIONs}

The amount of cellular SPION uptake was previously shown to depend on the concentration of SPIONs within the cell culture medium. ${ }^{24}$ To evaluate the suitability of each method to quantify cellular or cell-associated magnetic particles, as well as to correlate those findings with the flow cytometry analysis of the side scatter, HUVECs were treated with $0-100 \mu \mathrm{g}_{\mathrm{Fe}} / \mathrm{mL}$ SPIONs for 48 hours (Figure $2 \mathrm{~A}-\mathrm{C}$ ). Within the tested concentration range, the cellular uptake of SEON ${ }^{\mathrm{LA}}$ and SEON ${ }^{\mathrm{LA}-\mathrm{BSA}}$ by HUVECs directly correlated with the SPION concentration in the cell culture medium $\left(R^{2}>0.96\right.$,
$R^{2}>0.98$, and $R^{2}>0.97$ for the UVS, MPS, and AAS measurements, respectively, Figure 2, left and middle panel). In contrast, cell-associated Rienso ${ }^{\circledR}$ particles were hardly detectable by any of the methods (Figure 2, right panel). Even at the highest concentration, Rienso ${ }^{\circledR}$ particles were detected only with the AAS method, suggesting a very low uptake or binding of Rienso ${ }^{\circledR}$ to HUVECs.

In flow cytometry, cells can be morphologically characterized by forward scatter and side scatter, where the forward scatter is corresponding to cell "size" and the side scatter to "granularity" of the cell. As nanoparticles scatter light, it is possible to detect intracellular nanoparticles also by side scatter analysis in flow cytometry, if the side scatter increase of nanoparticle-treated cells compared with untreated cells surpasses the detection threshold (Table S1). Since the cellular size and granularity changes during cell death, it is necessary 
A

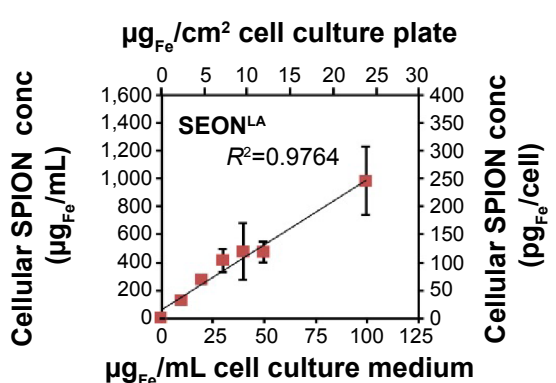

B

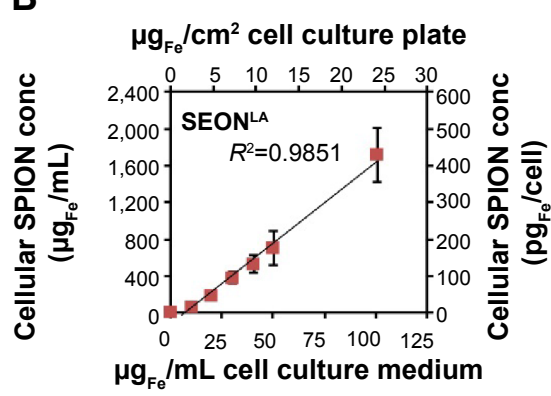

C

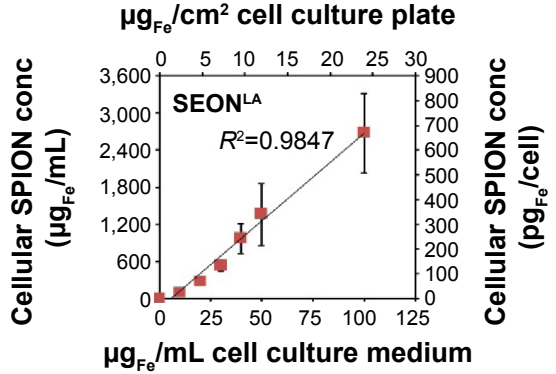

UVS

$\mu_{\mathrm{Fe}} / \mathrm{cm}^{2}$ cell culture plate

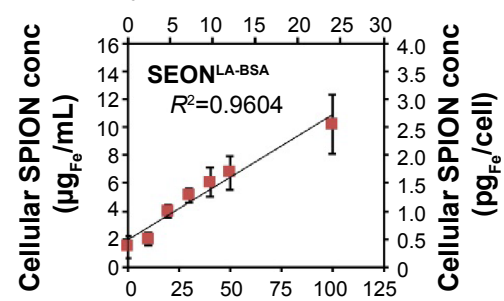

$\mu \mathrm{g}_{\mathrm{Fe}} / \mathrm{mL}$ cell culture medium

MPS

$\mu_{\mathrm{Fe}} / \mathrm{cm}^{2}$ cell culture plate

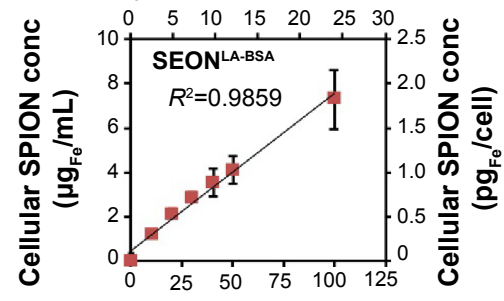

$\mu \mathrm{g}_{\mathrm{Fe}} / \mathrm{mL}$ cell culture medium

AAS

$\mu g_{\mathrm{Fe}} / \mathbf{c m}^{2}$ cell culture plate

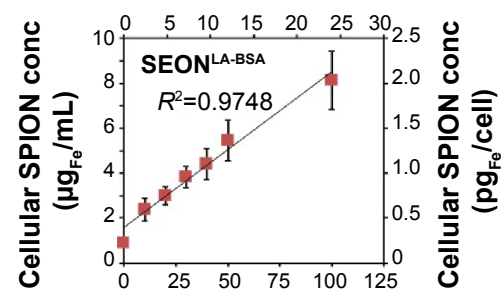

$\mu g_{\mathrm{Fe}} / \mathrm{mL}$ cell culture medium $\mu \mathrm{g}_{\mathrm{Fe}} / \mathrm{cm}^{2}$ cell culture plate

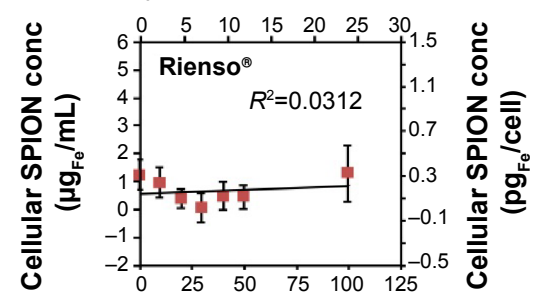

$\mu \mathrm{g}_{\mathrm{Fe}} / \mathrm{mL}$ cell culture medium

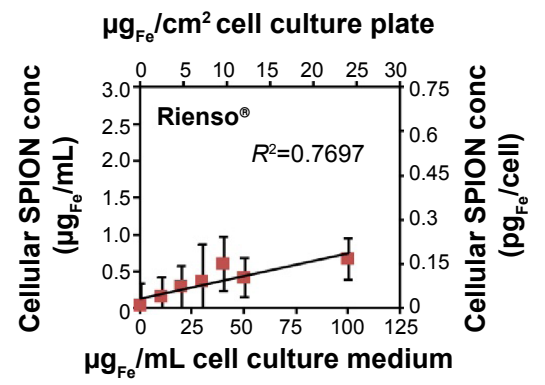

$\mu \mathrm{g}_{\mathrm{Fe}} / \mathrm{cm}^{2}$ cell culture plate

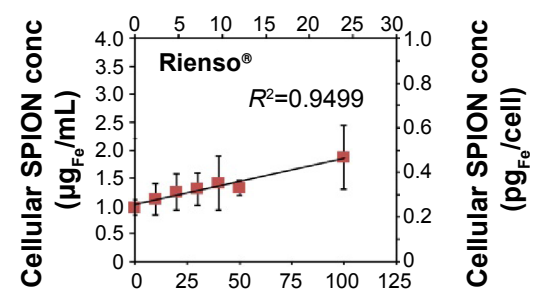

$\mu \mathrm{g}_{\mathrm{Fe}} / \mathrm{mL}$ cell culture medium

Figure 2 Concentration measurements of cellular SPIONs.

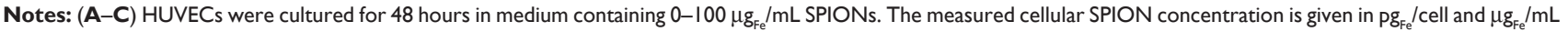
cell lysate and is correlated to the SPION concentration in medium indicated as $\mu \mathrm{g}_{\mathrm{fe}} / \mathrm{mL}$ medium and $\mu \mathrm{g}_{\mathrm{fe}} / \mathrm{cm}^{2}$ cell culture plate surface. Cellular SPION concentrations were measured with (A) UVS, (B) MPS, and (C) AAS. The columns present data acquired with SEON ${ }^{\perp A}$ (left panel), SEON ${ }^{L A-B S A}$ (middle panel), and Rienso ${ }^{\circledR}$ (right panel). Data are expressed as the mean \pm standard error ( $\mathrm{n}=3$ with technical triplicates). $R^{2}$ represents the coefficient of determination.

Abbreviations: SPION, superparamagnetic iron oxide nanoparticle; UVS, ultraviolet spectrophotometry; MPS, magnetic particle spectroscopy; AAS, atomic adsorption spectroscopy; SEON ${ }^{\perp A}$, lauric acid-coated nanoparticles; SEON ${ }^{L A-B S A}$, lauric acid/albumin bovine serum hybrid-coated nanoparticles; HUVECs, human umbilical vein endothelial cells.

to exclude dying or dead cells with altered morphology from analysis of the side scatter for SPION uptake. Gating on phenotypically healthy cells, characterized by negative Annexin $\mathrm{V}$ and negative propidium iodide staining, a significant correlation was observed between the SPION amount in the cell culture medium and the side scatter of viable cells after 48 hours of incubation with SEON ${ }^{\mathrm{LA}-\mathrm{BSA}}\left(R^{2}>0.97\right)$. The SEON ${ }^{\mathrm{LA}}$ data demonstrated a similar correlation when narrowing the analysis to cells with a SPION-load below $100 \mu \mathrm{g}_{\mathrm{Fe}} / \mathrm{mL}\left(R^{2}>0.99\right.$; Figure $3 \mathrm{~A}$, left and middle panel). Cells incubated with Rienso ${ }^{\circledR}$ did not display a significant change in side scatter increase in response to the growing nanoparticle dose in the medium, confirming an extremely low cellular uptake or binding of these particles (Figure 3A, right panel), as compared with SEON ${ }^{\mathrm{LA}-\mathrm{BSA}}$ and $\mathrm{SEON}^{\mathrm{LA}}$ par- ticles. Figure $\mathrm{S} 3$ shows representative flow cytometric graphs of nanoparticle-treated cells, and highlights the principle of the side scatter increase after nanoparticle attachment/ uptake by cells.

Consequently, when the side scatter data were plotted against the results of the AAS measurements, a strong dependence between side scatter and cellular SPION-load for $\operatorname{SEON}^{\mathrm{LA}}\left(R^{2}>0.94\right)$ and SEON ${ }^{\mathrm{LA}-\mathrm{BSA}}\left(R^{2}>0.99\right)$ particles was confirmed, whereas Rienso ${ }^{\circledR}$ did not show any correlation tendency (Figure 3B). Similar results were achieved when side scatter data were plotted against the results of the UVS and MPS measurements, demonstrating the applicability of these methods for calibration of the flow cytometry side scatter measurements (Figure S4A and B). 
A

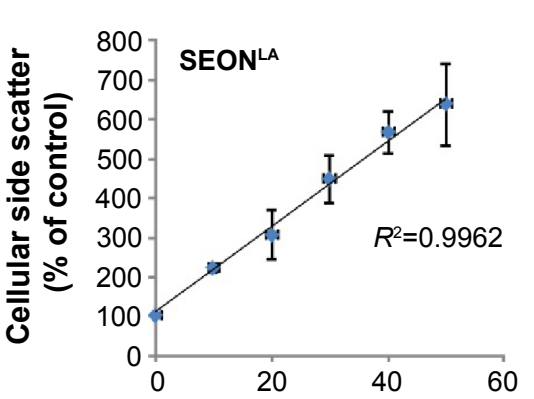

$\mu g_{\mathrm{Fe}} / \mathrm{mL}$ cell culture medium
Side scatter vs SPION concentration in cell culture medium

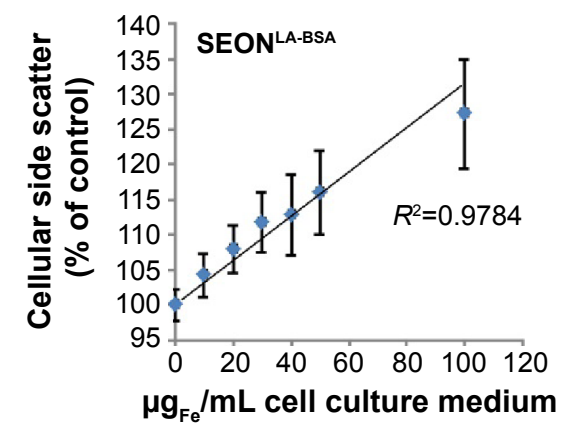

B

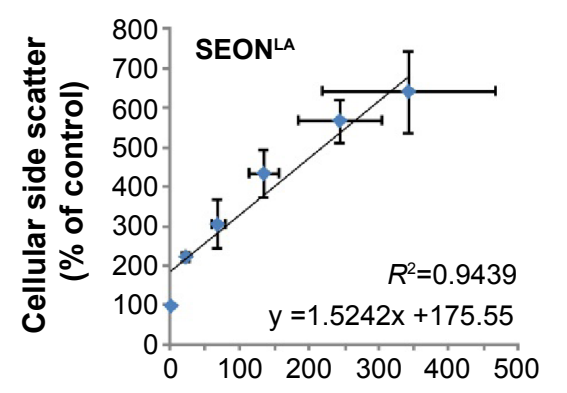

Cellular SPION conc $\left(\mathrm{pg}_{\mathrm{Fe}}\right.$ /cell)

\section{Side scatter vs cellular SPION concentration}

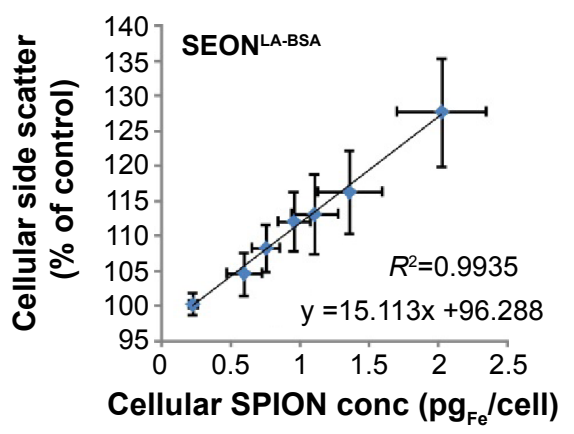

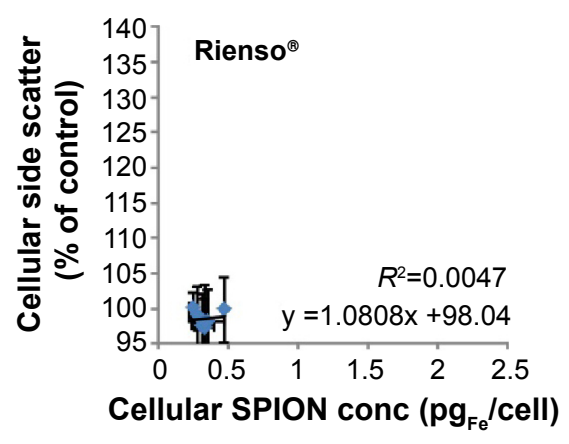

Figure 3 Correlation between side scatter measurements and SPION-loads. HUVECs were cultured for 48 hours in medium containing 0-I00 $\mu \mathrm{g}_{\mathrm{Fe}} / \mathrm{mL} \mathrm{SPIONs.}$ Notes: (A) Correlation of the side scatter and the SPION concentration within the cell culture medium. (B) Relationship between the cellular SPION-load as measured by AAS and the normalized side scatter data delivered by flow cytometry. Results were acquired with SEON ${ }^{L A}$ (left panel), SEON LA-BSA (middle panel), and Rienso ${ }^{\circledR}$ (right panel). Data are expressed as the mean \pm standard error ( $\mathrm{n}=3$ with technical triplicates). $R^{2}$ represents the coefficient of determination. $y$ describes the mathematic relationship between side scatter and cellular SPION content.

Abbreviations: SPION, superparamagnetic iron oxide nanoparticle; AAS, atomic adsorption spectroscopy; HUVECs, human umbilical vein endothelial cells; SEON ${ }^{L A}$, lauric acid-coated nanoparticles; SEON ${ }^{\text {LA-BSA }}$, lauric acid/albumin bovine serum hybrid-coated nanoparticles.

\section{Cell viability is strongly dependent on SPION type}

Flow cytometry is a rapid and comprehensive method for analysis of multiple toxicity parameters. The absolute amount of viable cells after treatment is a direct indicator of the toxic effect of SPIONs on cells. In our study, this parameter was routinely collected prior to determination of the cellular SPION-load and other toxicity parameters using the MUSE Cell Analyzer (Figure 4A). Interestingly, incubation of cells with SEON ${ }^{\mathrm{LA}}$ for 48 hours resulted in dramatic inhibition of proliferation, whereas this effect was much less pronounced upon increasing SEON ${ }^{\text {LA-BSA }}$ treatment and absent with Rienso ${ }^{\circledR}$ particles.

A detailed analysis of the toxic effects of SPIONs was performed using multiparameter flow cytometry (Figure 4B-D). ${ }^{25-27}$ Annexin V and propidium iodide staining of HUVECs revealed a very low tendency of SEON ${ }^{\mathrm{LA}-\mathrm{BSA}}$ and Rienso ${ }^{\circledR}$ particles to induce cell death (Figure 4B), whereas treatment of HUVECs with SEON ${ }^{\mathrm{LA}}$ had a stronger effect on viability. Interestingly, $n$ SEON ${ }^{L A}$-treated cells only the rate of apoptotic cells increased in a dose-dependent manner, whereas the amount of necrotic cells stayed almost constant. Thus, after incubation for 48 hours, the amount of viable cells dropped continuously to $41 \%$ in the presence of the highest SEON ${ }^{\mathrm{LA}}$ concentration.

Cells analyzed by DiIC1(5) staining $^{15}$ revealed only a slight effect of SEON ${ }^{\text {LA-BSA }}$ and Rienso ${ }^{\circledR}$ particles on the membrane potential (Figure 4C). Again, incubation with SEON $^{\mathrm{LA}}$ particles had severe consequences for cell viability by inducing a dose-dependent collapse of the membrane potential and, ultimately, cell death.

Finally, propidium iodide-Triton X measurements were performed to analyze cell cycle stage and DNA degradation during apoptosis (Figure 4D). ${ }^{28-30}$ Consistent with the aforementioned results, SEON ${ }^{\mathrm{LA}-\mathrm{BSA}}$ and Rienso ${ }^{\circledR}$ did not significantly influence the cell cycle or DNA degradation. In contrast, treatment with SEON ${ }^{\mathrm{LA}}$ induced a concentrationdependent increase in numbers of damaged cells in subG1phase, reflecting the DNA degradation due to induction of cell death. Taken together, the flow cytometry analysis 

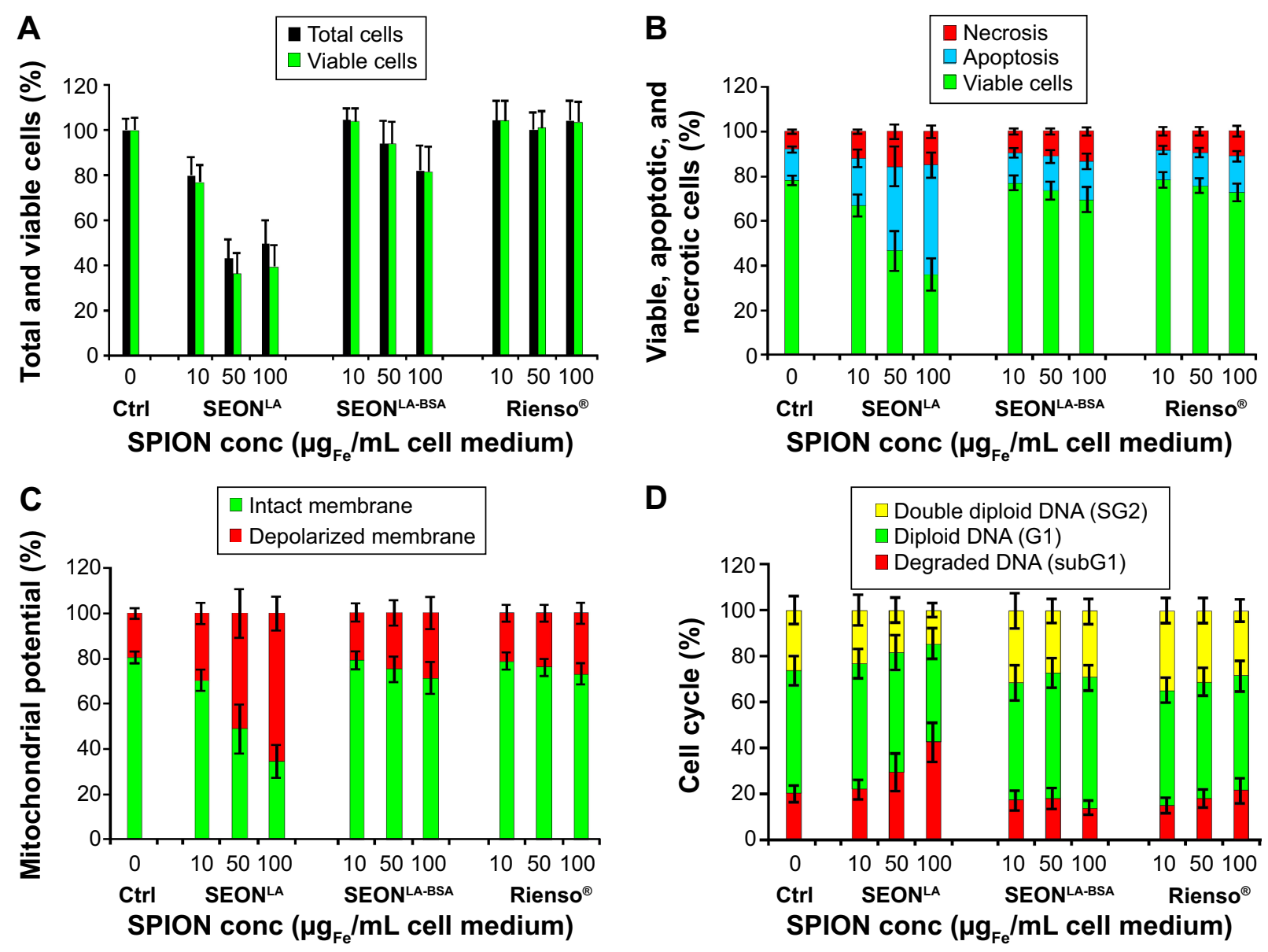

Figure 4 Association of cellular uptake with toxicity of SPIONs. HUVECs were incubated for 48 hours with different amounts of SPIONs and cytotoxicity was analyzed by flow cytometry.

Notes: (A) Quantification of the absolute amount of total cell numbers and viable cells using MUSE. (B) Cell viability determined by Annexin V/propidium iodide staining. Percentages of necrotic (propidium iodide-positive), apoptotic (Annexin V-positive, propidium iodide-negative) and viable cells (Annexin V-negative, propidium iodide-negative)

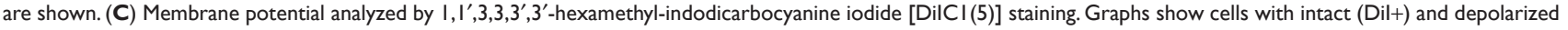
(Dil-) membrane potential. (D) Cell cycle analysis by propidium iodide-Triton X staining. The cell status is expressed as the amount of apoptotic (degraded DNA, subGI), diploid (GI-phase) and double diploid (synthesis/G2 phase) cells. Data are presented as the mean \pm standard error ( $\mathrm{n}=3$ with sample triplicates). The results were normalized to total cells (A) or to untreated control cells (B-D), set to 100\%.

Abbreviations: SPION, superparamagnetic iron oxide nanoparticle; HUVECs, human umbilical vein endothelial cells; SEON ${ }^{L A}$, lauric acid-coated nanoparticles; SEON ${ }^{L A-B S A}$, lauric acid/albumin bovine serum hybrid-coated nanoparticles; ctrl, control.

indicated a very low cytotoxic impact of SEON ${ }^{\mathrm{LA}-\mathrm{BSA}}$ and Rienso on HUVECs, corresponding to low cellular uptake, as estimated by side scatter analysis and other techniques. In contrast, $\mathrm{SEON}^{\mathrm{LA}}$ particles, in parallel with increasing cellular uptake, resulted in a strong cellular response and a dose-dependent induction of cell death.

\section{Discussion}

One of the most important considerations related to use of SPIONs in humans is their potential toxicity. As such, the toxic effects of SPIONs have been investigated ever since their first clinical applications in the 1980s. ${ }^{31-34}$ In vitro studies, summarized by Bulte et al indicated no toxic effects of SPIONs at concentrations below $10 \mathrm{pg}_{\mathrm{Fe}} / \mathrm{cell}^{35}$ In endothelial cells, treatment with up to $100 \mu \mathrm{g}_{\mathrm{Fe}} / \mathrm{mL}$ SPIONs was well tolerated, although cellular uptake was not determined in that study. ${ }^{36}$ During clinical applications like magnetic resonance imaging or magnetic hyperthermia, SPIONs come into direct contact with endothelial cells when administered into veins or arteries. We therefore investigated SPION accumulation/ uptake in endothelial cells, which are the first contact cells for all nanoparticles intended for intravascular administration.

Since the interest in iron oxide nanoparticles for technical, scientific, and medical applications is increasing, there is an urgent need for reliable and rapid methods to characterize those particles before further development and use. Thus, correlation of the cellular SPION amount with cellular effects requires accurate quantification. However, the majority of laboratories have no access to high-end quantification techniques such as AAS and MPS, and being 
compelled to reduce costs, are restricted to other techniques, eg, spectrophotometry.

Photometric quantification of SPIONs within cell lysates was originally established using particles coated either with dextran or with a semisynthetic carbohydrate PSC. ${ }^{22}$ As the coating of SPIONs might influence their absorption behavior, we investigated the reproducibility of this method for SEON nanoparticles coated with either lauric acid or lauric acid and bovine serum albumin in parallel with Rienso ${ }^{\circledR}$ particles coated with PSC. We observed similar absorption spectra and an absorption maximum at $370 \mathrm{~nm}$ for all three SPION types, indicating only a very slight influence of the coating on absorption intensity at $\mathrm{OD}_{370}$ (Figure $\mathrm{S} 2 \mathrm{~A}$ ). Moreover, for all three types of nanoparticles, we found an almost perfect correlation between SPION concentration and SPION absorbance, which is a prerequisite for reliable SPION quantification.

Other factors that could theoretically influence the results of photometric quantification of SPIONs in cell lysates are the components of the lysate itself. Degradation products of cellular components might absorb light and potentially alter the result of SPION quantification. Although nucleic acids and proteins are usually quantified by absorption measurements at $260 \mathrm{~nm}$ and $280 \mathrm{~nm}$, respectively, their interference with the SPION quantification method cannot be completely excluded. ${ }^{37,38}$ However, the enormous similarity between measurements of SPIONs in the lysis buffer and in the HUVEC lysates (Figures S2B-D; 1A-C) confirms the reliability of the photometric SPION quantification in cell lysates, proving the absence of compounds able to interfere with quantification of SPIONs in these conditions. Furthermore, we demonstrated that the results obtained with the UVS method are consistent with those of highly precise techniques like AAS and MPS. All three methods deliver comparable results for the cellular SEON ${ }^{\mathrm{LA}-\mathrm{BSA}}$ and SEON ${ }^{\mathrm{LA}}$ content of HUVECs (Figure 1A-B). In cell lysates containing very small amounts of SPIONs, eg, Rienso ${ }^{\circledR}$-treated HUVEC lysates, the slightly poorer detection limit of the UVS method prevented a reliable quantification (Figure 1C). Here, AAS and especially MPS have a clear advantage over the UVS method and are thus more suitable for detection of trace amounts of SPIONs within cell lysates. A strong advantage of the UVS technique, however, is the low costs of the equipment required, ie, a plate reader in comparison with the MPS or AAS instrument.

With regard to cellular uptake, the data presented here underline type-specific SPION internalization into HUVECs, which result from a combination of SPION concentration and particle coating. Even though the cellular SPION concentration strongly differed depending on the SPION type, SEON ${ }^{\mathrm{LA}-\mathrm{BSA}}$ and Rienso ${ }^{\circledR}$ were principally non-toxic even at very high concentrations. In contrast, $\mathrm{SEON}^{\mathrm{LA}}$ were toxic already at significantly lower concentrations in the cell culture medium, as determined by multiparameter flow cytometry (Figure 4). SEON ${ }^{\mathrm{LA}}$ treatment induced a dosedependent increase in numbers of apoptotic cells in parallel with membrane depolarization and the amounts of degraded DNA. Moreover, analysis of biostability displayed highly agglomeration-prone behavior of SEON ${ }^{\mathrm{LA}}$, which was not observable with SEON ${ }^{\text {LA-BSA }}$ and Rienso ${ }^{\circledR}$ particles (Table 1; Figure S1E-G). These properties were independent of zeta potential values, which did not differ between the three types of nanoparticles, indicating that the zeta potential cannot generally be considered for estimating the stability of colloids. It must be noted that SEON ${ }^{\mathrm{LA}}$ particles contain a bilayer of lauric acid on the particle surface. The outer layer of surfactant is in permanent equilibrium with the solution. After dilution in any type of medium, the outer layer is gradually removed from the particles, thus causing particle-precipitation within minutes or few hours (depending on the degree of particle dilution and/or ionic strength of the diluent). Complex biological fluids, containing proteins to which excess lauric acid can adsorb permanently, can accelerate this process even further. ${ }^{20,39}$

One of the parameters routinely determined by flow cytometry is the side scatter. Gating on phenotypically healthy cells, characterized by Annexin V-negative and propidium iodide-negative staining, delivered a significant correlation of the side scatter data with cellular SPION content in cells incubated with increasing amounts of SEON ${ }^{\mathrm{LA}}$ and SEON ${ }^{\text {LA-BSA }}$ (Figure 3A).

This semiquantitative determination could be further enhanced by calibrating the side scatter parameter for a certain cell type and SPION type. This calibration should preferably be made after quantification of the cellular SPIONload by AAS, but MPS and UVS also deliver accurate data. Based on our results, scatter analysis is a reliable method to quantitatively determine the cellular amount of SPIONs (Figures 3B, S4A-B). Naturally, this is only possible if sufficient amounts of particles are internalized and the detection threshold of the side scatter analysis is surpassed. Thus, no measurable change in the side scatter of HUVECs incubated with Rienso ${ }^{\circledR}$ was detectable, indicating an extremely low uptake of these particles (Figure 3, left panel).

It must be noted that in previously published studies, cellular uptake of SPIONs was normalized to protein 
concentration. ${ }^{36}$ However, to obtain a better understanding of the influence of nanoparticles on cells, it is crucial to gather all relevant concentration parameters, such as $\mu \mathrm{g}_{\mathrm{Fe}} / \mathrm{mL}$ media, $\mu \mathrm{g}_{\mathrm{Fe}} / \mathrm{cm}^{2}$ plate surface, and $\mathrm{pg}_{\mathrm{Fe}} /$ cell and, above all, the respective cell number of the measured sample. The methods applied in our study aimed at quantification of cell numbers in parallel with the measurement of SPION content, in order to correlate the cellular effects with the average amount of SPIONs per cell. This approach enabled correlation of the supplemented iron concentration with the cellular SPION uptake and thus an easy conversion of cellular SPION concentration from $\mu \mathrm{g}_{\mathrm{Fe}} / \mathrm{mL}$ lysate to $\mathrm{pg}_{\mathrm{Fe}} /$ cell (Figure 2). Counting the cell number within samples is particularly important in order to correlate SPION toxicity with the cellular iron content. As cytotoxic effects could lead to a detachment of cells, we ensured that all cells were collected for measurements to prevent misinterpretation of the results.

In conclusion, flow cytometry is the gold standard to investigate the cellular impact of nanoparticles, since it is the most efficient method to simultaneously determine several different toxicity parameters. Our findings indicate that, together with the side scatter data, and the possibility to correlate those data with the cellular SPION amount, flow cytometry could serve as a platform for medium to high throughput screening of SPIONs.

\section{Acknowledgments}

We thank Sibylle Bremer-Streck at the Institut für Klinische Chemie und Laboratoriumsdiagnostik in Jena for technical assistance with the AAS measurements. This study was supported by the Deutsche Forschungsgemeinschaft (SPP1681 [AL 552/5-1, TR 408/8-1], OD 18/23-1, HI 698/7-4, TR 408/4-3, CI162/2-1), by the Bavarian State Ministry for Environment and Consumer Protection, and the Deutsche Forschungsgemeinschaft Cluster of Excellence-Engineering of Advanced Materials (EAM).

\section{Disclosure}

The authors report no conflicts of interest in this work.

\section{References}

1. Jin R, Lin B, Li D, Ai H. Superparamagnetic iron oxide nanoparticles for MR imaging and therapy: design considerations and clinical applications. Curr Opin Pharmacol. 2014;18C:18-27.

2. Thomas R, Park IK, Jeong YY. Magnetic iron oxide nanoparticles for multimodal imaging and therapy of cancer. Int J Mol Sci. 2013;14: 15910-15930.

3. Schutz CA, Juillerat-Jeanneret L, Mueller H, Lynch I, Riediker M. NanoImpactNet Consortium. Therapeutic nanoparticles in clinics and under clinical evaluation. Nanomedicine (Lond). 2013;8:449-467.
4. Grillo R, Rosa AH, Fraceto LF. Engineered nanoparticles and organic matter: a review of the state-of-the-art. Chemosphere. 2014;119C: 608-619.

5. Sarkar A, Ghosh M, Sil PC. Nanotoxicity: oxidative stress mediated toxicity of metal and metal oxide nanoparticles. J Nanosci Nanotechnol. 2014;14:730-743.

6. Kumar A, Dhawan A. Genotoxic and carcinogenic potential of engineered nanoparticles: an update. Arch Toxicol. 2013;87:1883-1900.

7. Mayhew TM, Muhlfeld C, Vanhecke D, Ochs M. A review of recent methods for efficiently quantifying immunogold and other nanoparticles using TEM sections through cells, tissues and organs. Ann Anat. 2009;191:153-170.

8. Burrows ND, Penn RL. Cryogenic transmission electron microscopy: aqueous suspensions of nanoscale objects. Microsc Microanal. 2013;19: $1542-1553$.

9. Stender AS, Marchuk K, Liu C, et al. Single cell optical imaging and spectroscopy. Chem Rev. 2013;113:2469-2527.

10. Rad AM, Janic B, Iskander AS, Soltanian-Zadeh H, Arbab AS. Measurement of quantity of iron in magnetically labeled cells: comparison among different UV/VIS spectrometric methods. Bio Techniques. 2007;43:627-628, 630, 632.

11. Wiekhorst F, Steinhoff U, Eberbeck D, Trahms L. Magnetorelaxometry assisting biomedical applications of magnetic nanoparticles. Pharm Res. 2012;29:1189-1202.

12. Tietze R, Jurgons R, Lyer S, et al. Quantification of drug-loaded magnetic nanoparticles in rabbit liver and tumor after in vivo administration. J Magn Magn Mater. 2009;321:1465-1468.

13. Canfranc E, Abarca A, Sierra I, Marina ML. Determination of iron and molybdenum in a dietetic preparation by flame AAS after dry ashing. J Pharm Biomed Anal. 2001;25:103-108.

14. Janko C, Munoz L, Chaurio R, et al. Navigation to the graveyardinduction of various pathways of necrosis and their classification by flow cytometry. Methods Mol Biol. 2013;1004:3-15.

15. Munoz LE, Maueroder C, Chaurio R, Berens C, Herrmann M, Janko C. Colourful death: six-parameter classification of cell death by flow cytometry - dead cells tell tales. Autoimmunity. 2013;46:336-341.

16. Xia J, Zhang S, Zhang Y, et al. The relationship between internalization of magnetic nanoparticles and changes of cellular optical scatter signal. J Nanosci Nanotechnol. 2008;8:6310-6315.

17. Suzuki H, Toyooka T, Ibuki Y. Simple and easy method to evaluate uptake potential of nanoparticles in mammalian cells using a flow cytometric light scatter analysis. Environ Sci Technol. 2007;41: 3018-3024.

18. Zucker RM, Daniel KM, Massaro EJ, Karafas SJ, Degn LL, Boyes WK. Detection of silver nanoparticles in cells by flow cytometry using light scatter and far-red fluorescence. Cytometry A. 2013;83:962-972.

19. Toduka Y, Toyooka T, Ibuki Y. Flow cytometric evaluation of nanoparticles using side-scattered light and reactive oxygen species-mediated fluorescence - correlation with genotoxicity. Environ Sci Technol. 2012; 46:7629-7636.

20. Zaloga J, Janko C, Nowak J, et al. Development of a lauric acid/albumin hybrid iron oxide nanoparticle system with improved biocompatibility. Int J Nanomed. 2014;9:4847-4866.

21. Matuszak J, Zaloga J, Friedrich RP, et al. Endothelial biocompatibility and accumulation of SPION under flow conditions. J Magn Magn Mater. doi:10.1016/j.jmmm. 2014. Available from: http://www.sciencedirect.com/science/article/pii/S0304885314008245

22. Dadashzadeh ER, Hobson M, Henry Bryant L Jr, Dean DD, Frank JA. Rapid spectrophotometric technique for quantifying iron in cells labeled with superparamagnetic iron oxide nanoparticles: potential translation to the clinic. Contrast Media Mol Imaging. 2013;8:50-56.

23. Riccardi C, Nicoletti I. Analysis of apoptosis by propidium iodide staining and flow cytometry. Nat Protoc. 2006;1:1458-1461.

24. Petri-Fink A, Chastellain M, Juillerat-Jeanneret L, Ferrari A, Hofmann H. Development of functionalized superparamagnetic iron oxide nanoparticles for interaction with human cancer cells. Biomaterials. 2005;26: 2685-2694. 
25. vanEngelandM,NielandLJ, RamaekersFC, SchutteB, ReutelingspergerCP. Annexin V-affinity assay: a review on an apoptosis detection system based on phosphatidylserine exposure. Cytometry. 1998;31:1-9.

26. Demchenko AP. The change of cellular membranes on apoptosis: fluorescence detection. Exp Oncol. 2012;34:263-268.

27. Bohm I, Traber F, Block W, Schild H. [Molecular imaging of apoptosis and necrosis - basic principles of cell biology and use in oncology]. Rofo. 2006;178:263-271. German.

28. Pozarowski P, Darzynkiewicz Z. Analysis of cell cycle by flow cytometry. Methods Mol Biol. 2004;281:301-311.

29. Ormerod MG. Investigating the relationship between the cell cycle and apoptosis using flow cytometry. J Immunol Methods. 2002;265: 73-80.

30. Nunez R. DNA measurement and cell cycle analysis by flow cytometry. Curr Issues Mol Microbiol. 2001;3:67-70.

31. Weir MP, Gibson JF, Peters TJ. Haemosiderin and tissue damage. Cell Biochem Funct. 1984;2:186-194.

32. Bassett ML, Halliday JW, Powell LW. Value of hepatic iron measurements in early hemochromatosis and determination of the critical iron level associated with fibrosis. Hepatology. 1986;6:24-29.
33. Weissleder R, Stark DD, Engelstad BL, et al. Superparamagnetic iron oxide: pharmacokinetics and toxicity. AJR Am J Roentgenol. 1989;152: 167-173.

34. Fischer R, Piga A, Harmatz P, Nielsen P. Monitoring long-term efficacy of iron chelation treatment with biomagnetic liver susceptometry. Ann N Y Acad Sci. 2005;1054:350-357.

35. Bulte JW. In vivo MRI cell tracking: clinical studies. AJR Am J Roentgenol. 2009;193:314-325.

36. Sun Z, Yathindranath V, Worden M, et al. Characterization of cellular uptake and toxicity of aminosilane-coated iron oxide nanoparticles with different charges in central nervous systemrelevant cell culture models. Int J Nanomedicine. 2013;8:961-970.

37. Wilfinger WW, Mackey K, Chomczynski P. Effect of $\mathrm{pH}$ and ionic strength on the spectrophotometric assessment of nucleic acid purity. Bio Techniques. 1997;22:474-476, 478-481.

38. Stoscheck CM. Quantitation of protein. Methods Enzymol. 1990;182: 50-68.

39. Shen L, Laibinis PE, Hatton TA. Bilayer surfactant stabilized magnetic fluids: synthesis and interactions at interfaces. Langmuir. 1998;15: 447-453. 


\section{Supplementary materials}

Table SI Detection thresholds for UVS, MPS, AAS, and SSc

\begin{tabular}{lllll}
\hline Quantification method & Detection threshold unit $(\boldsymbol{\varnothing}+\mathbf{3} \sigma)$ & SEON $^{\text {LA }}$ & SEON $^{\text {LA-BSA }}$ & Rienso $^{\circledR}$ \\
\hline UVS & $\left(\mu \mathrm{g}_{\mathrm{Fe}} / \mathrm{mL}\right)$ & 4.47 & 4.74 & 4.03 \\
MPS & $\left(\mu \mathrm{g}_{\mathrm{Fe}} / \mathrm{mL}\right)$ & 0.49 & 0.31 & 2.52 \\
AAS & $\left(\mu \mathrm{g}_{\mathrm{Fe}} / \mathrm{mL}\right)$ & 0.56 & 0.56 & 0.56 \\
SSC & $(\%)$ & 110.48 & 109.16 & 112.11 \\
\hline
\end{tabular}

Notes: Detection threshold for the UVS, MPS, and AAS techniques with SPION-containing cell lysates indicated as $\mu g_{\mathrm{Fe}} / \mathrm{mL}$ cell lysate. The detection threshold for SSc analysis is indicated as the percentage compared with SSc data of untreated cells. The thresholds for UVS, MPS, and SSc is dependent on the SPION nature, whereas AAS, a method quantifying elementary iron, is not. Determinations of the detection threshold were achieved using the $3 \sigma$ criteria.

$\varnothing$, mean value of the negative control; $\sigma$, standard deviation.

Abbreviations: UVS, ultraviolet spectrophotometry; MPS, magnetic particle spectroscopy; AAS, atomic adsorption spectroscopy; SSc, side scatter analysis; SEONLA, lauric acid-coated nanoparticles; SEON ${ }^{\text {LA-BSA }}$, lauric acid/albumin bovine serum hybrid-coated nanoparticles; SPION, superparamagnetic iron oxide nanoparticle.

A
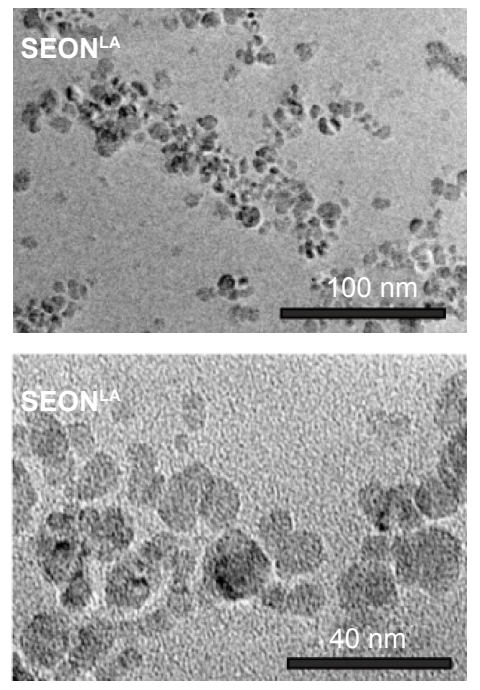

B

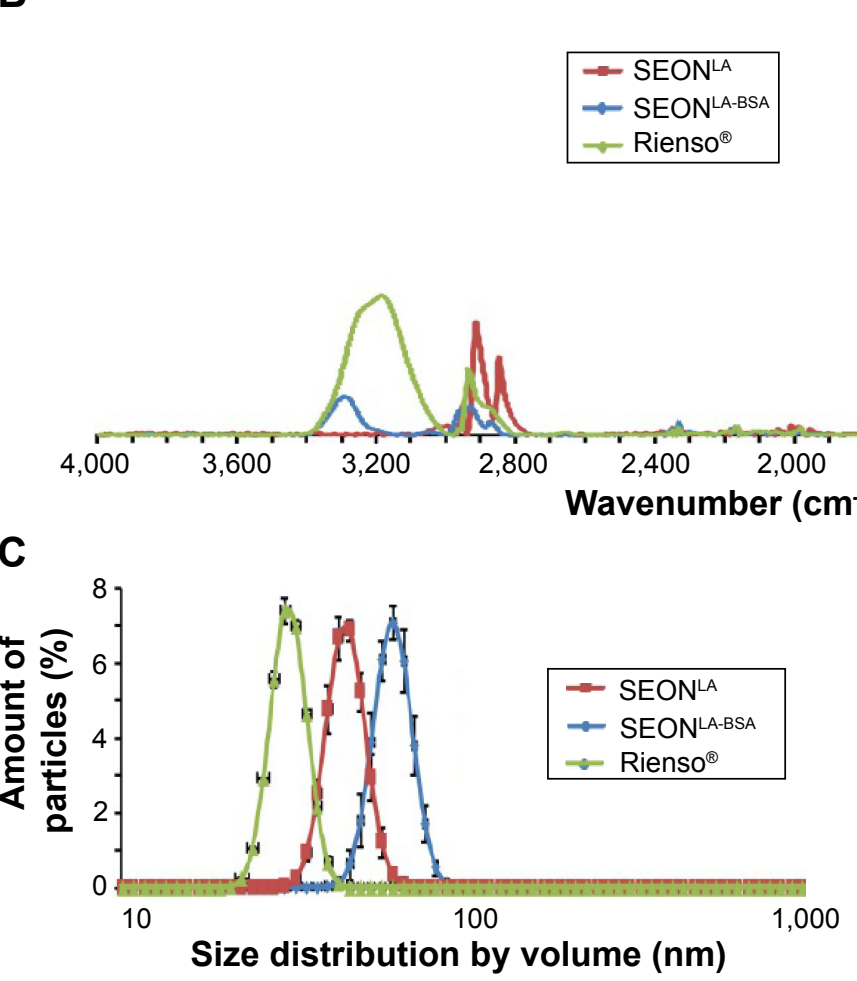

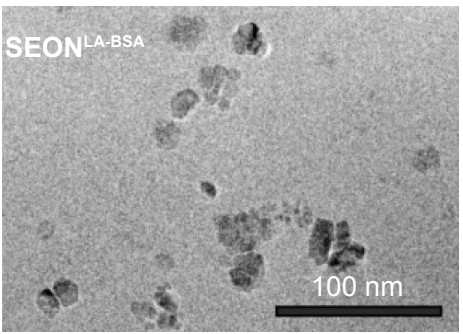
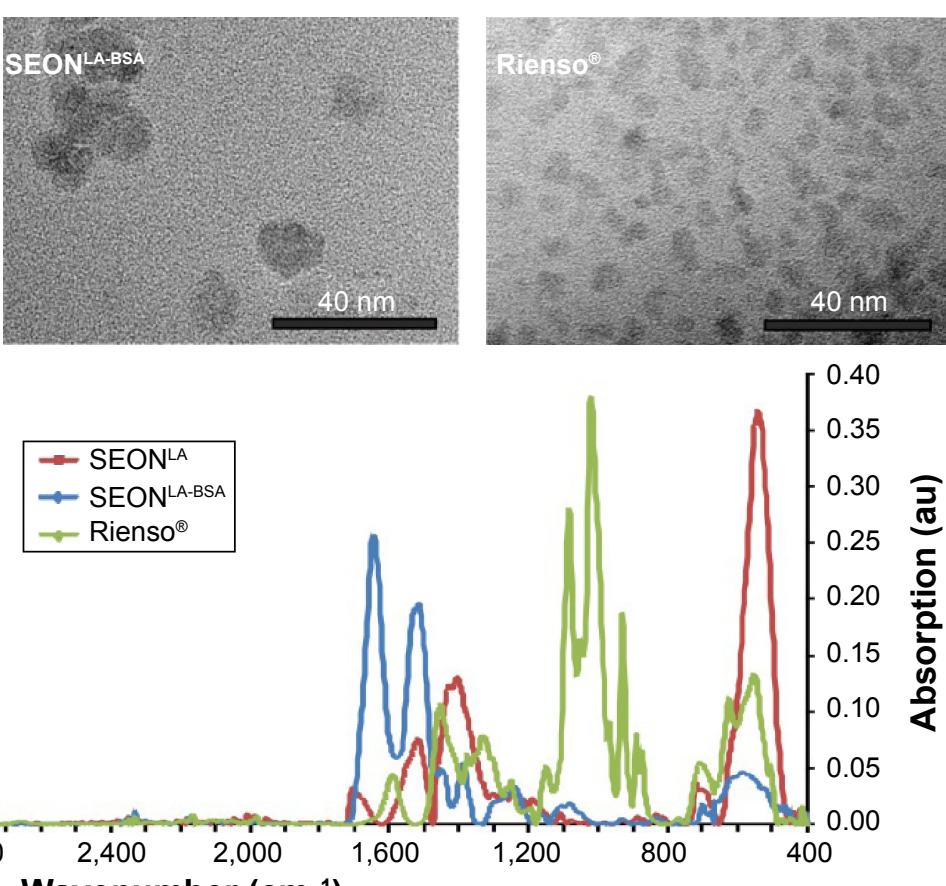
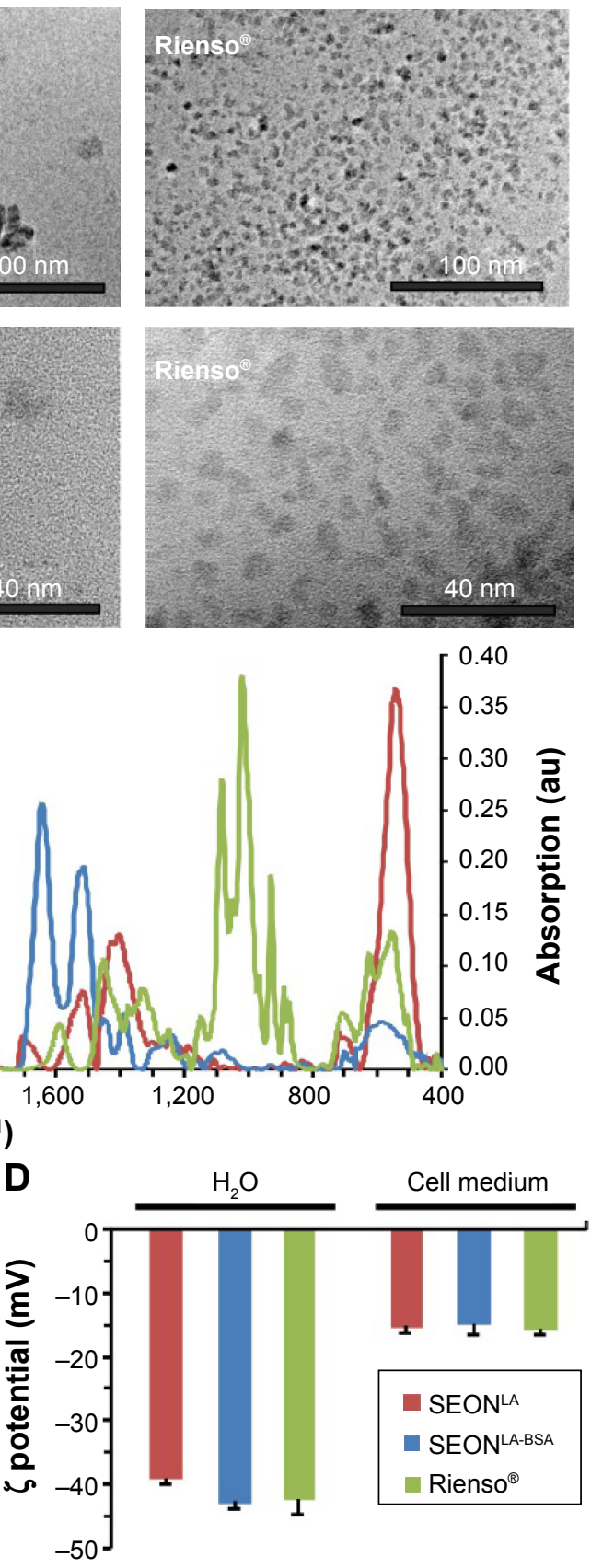

Figure SI (Continued) 
E

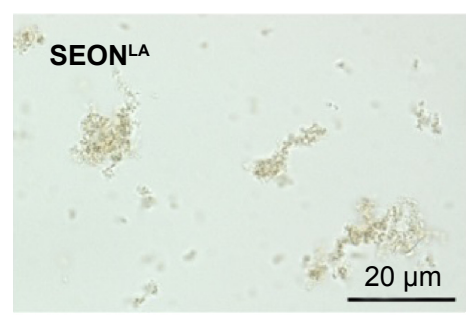

$\mathbf{F}$

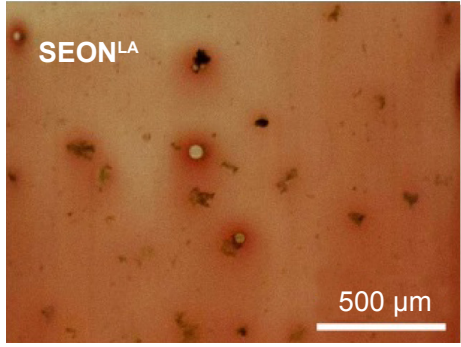

G

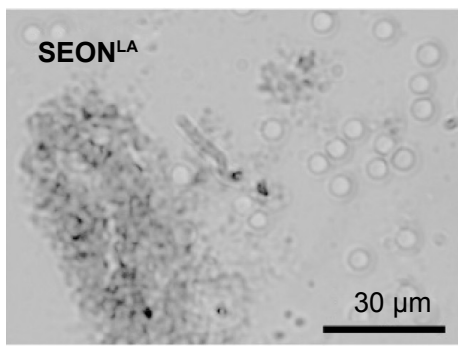

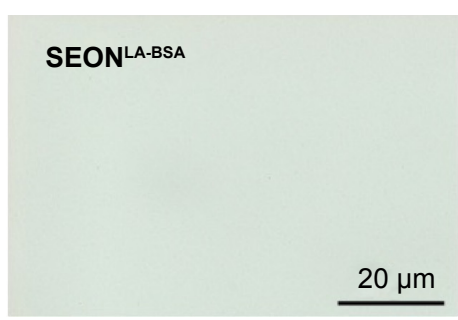
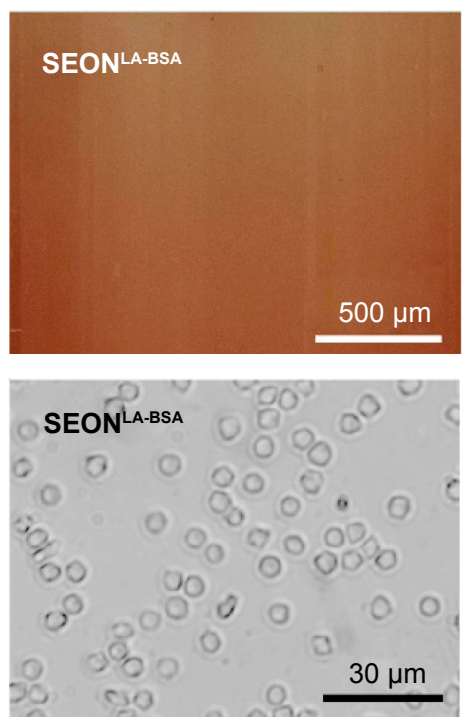
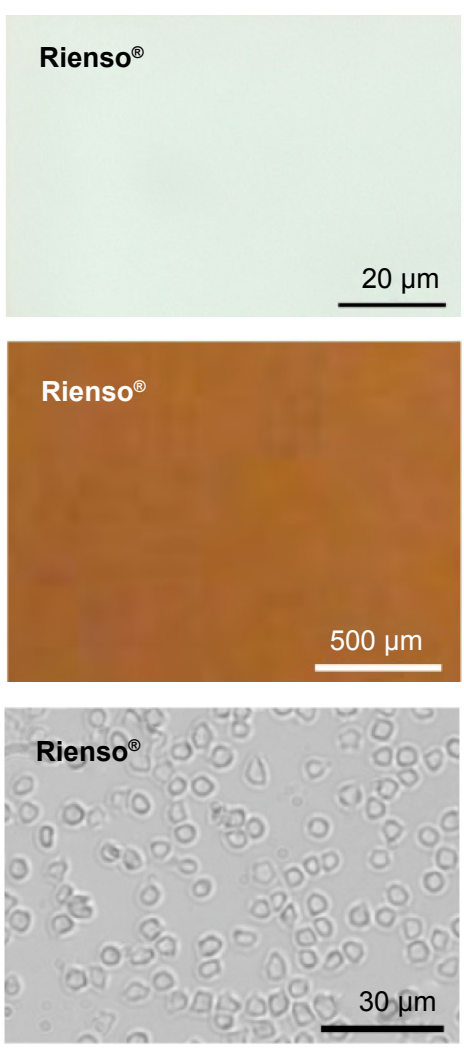

Figure SI Biophysical properties of SPIONs.

Notes: (A) Representative transmission electron micrographs of SEON ${ }^{L A-B S A}$, SEON ${ }^{L A}$ and Rienso ${ }^{\circledR}$. (B) Fourier transform infrared spectra of the nanoparticles. (C) Dynamic light scattering data of nanoparticles in water. (D) Zeta potential of investigated particles. (E-G) Biostability of nanoparticles. Nanoparticle stability was investigated in cell culture medium (E), and in ethylenediaminetetraacetic acid-stabilized sheep blood (F, G). Representative images were recorded using a digital camera $(\mathbf{F})$ and optical brightfield microscopy (E, G). Data are expressed as the mean \pm standard deviation $(n=3)$.

Abbreviations: au, absorbance units; SEON ${ }^{L A}$, lauric acid-coated nanoparticles; SEON ${ }^{L A-B S A}$, lauric acid/albumin bovine serum hybrid-coated nanoparticles; SPIONs, superparamagnetic iron oxide nanoparticles. 


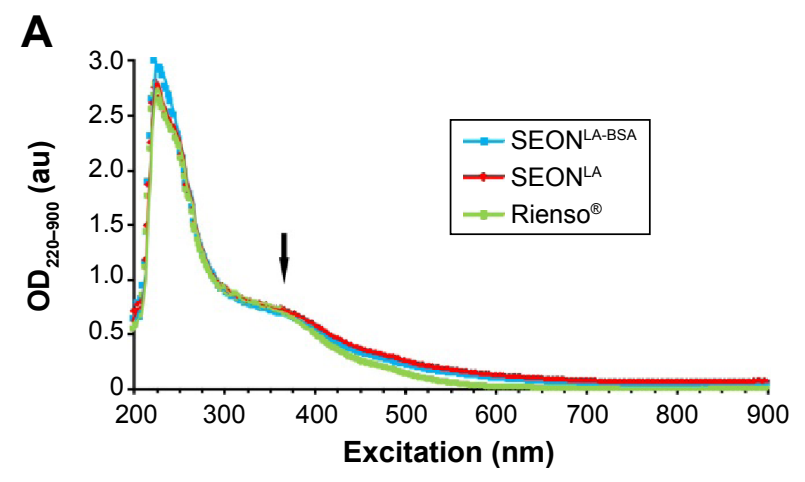

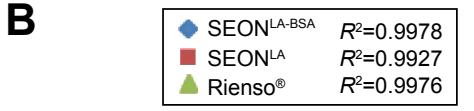

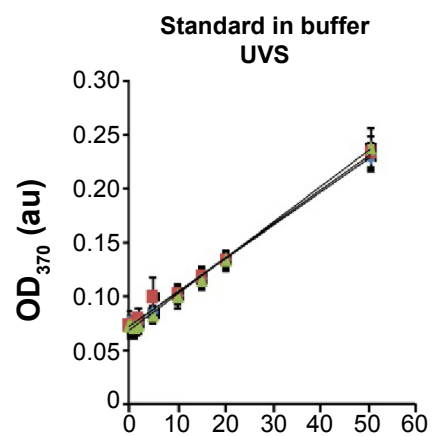

Concentration $\left(\mu \mathrm{g}_{\mathrm{Fe}} / \mathrm{mL}\right)$
C

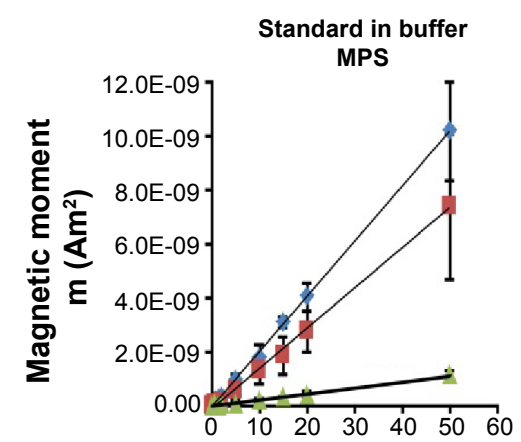

Concentration $\left(\mu \mathrm{g}_{\mathrm{Fe}} / \mathrm{mL}\right)$
D

\begin{tabular}{|ll|}
\hline SEON $^{L A-B S A}$ & $R^{2}=0.9997$ \\
SEON $^{L A}$ & $R^{2}=0.9895$ \\
$\triangle$ Rienso $^{\circledR}$ & $\Delta R^{2}=0.9988$ \\
\hline
\end{tabular}

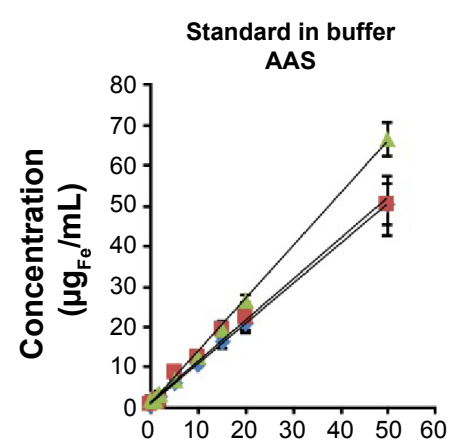

Concentration $\left(\mu \mathrm{g}_{\mathrm{Fe}} / \mathrm{mL}\right)$

Figure S2 Suitability of UVS, MPS, and AAS techniques for the measurement of SPION concentration in lysis buffer.

Notes: (A) Absorption spectra of SPIONs ( $30 \mu \mathrm{g}_{\mathrm{f}} / \mathrm{mL}$ ). Arrow indicates the absorption peak at $370 \mathrm{~nm}$. Correlation of UVS measurements at $370 \mathrm{~nm}$ (B), MPS measurements (C) and AAS measurements (D) with increasing SPION concentration in lysis buffer. Data are presented as mean \pm standard deviation ( $\mathrm{n}=3$ with triplicates). $R^{2}$ represents the coefficient of determination.

Abbreviations: SPION, superparamagnetic iron oxide nanoparticle; UVS, ultraviolet spectrophotometry; MPS, magnetic particle spectroscopy; AAS, atomic adsorption spectroscopy; SEON ${ }^{\perp A}$, lauric acid-coated nanoparticles; SEON ${ }^{\text {AA-BAA }}$, lauric acid/albumin bovine serum hybrid-coated nanoparticles; $\mathrm{OD}_{370}$, optical density at $370 \mathrm{~nm}$; au, absorbance units. 


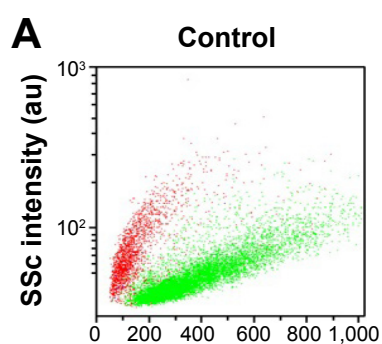

FSc intensity (au)
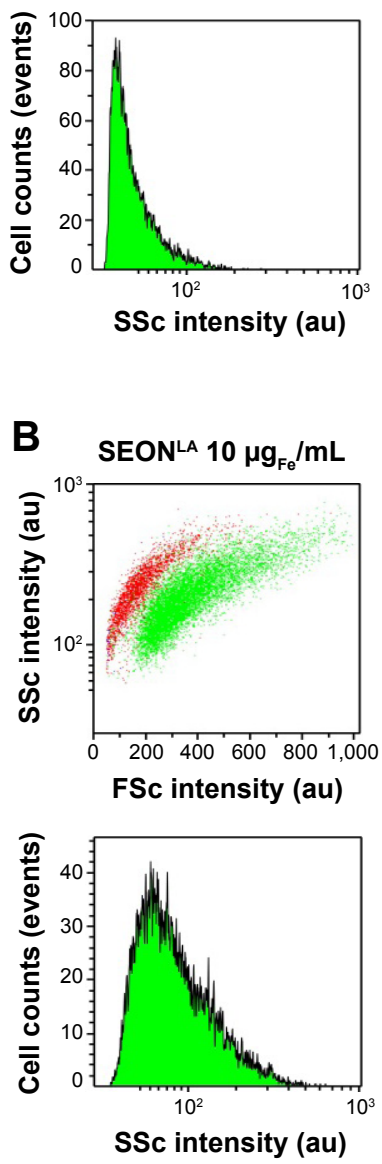
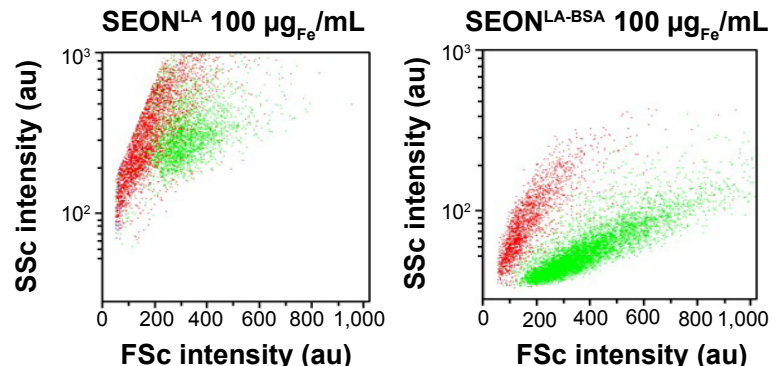

FSc intensity (au)

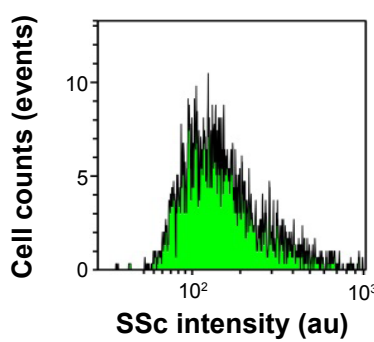

SSc intensity (au)

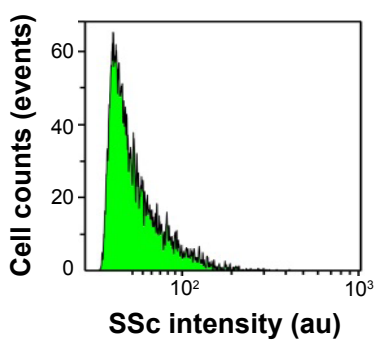

SSc intensity (au)
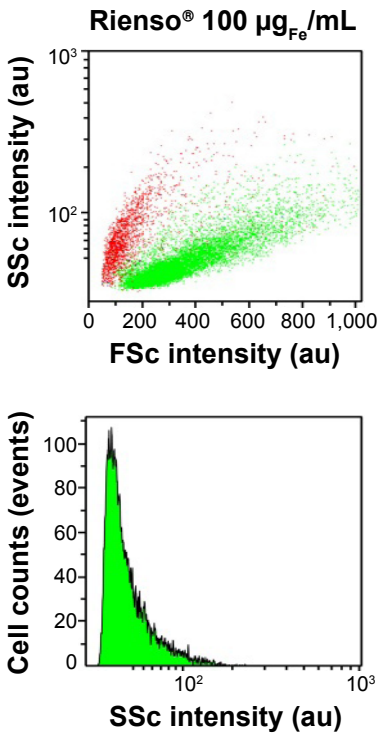

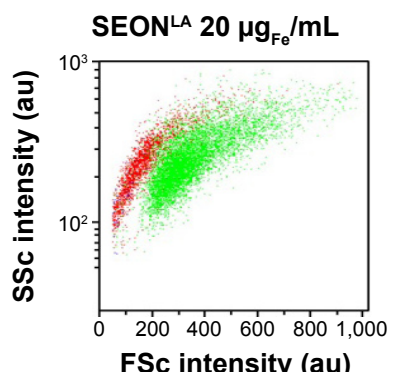

FSc intensity (au)

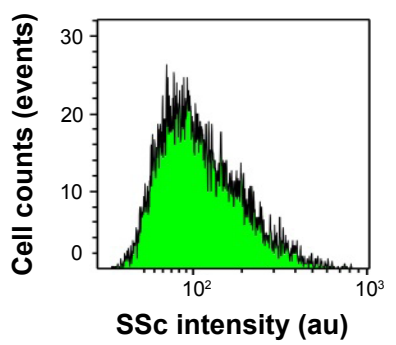

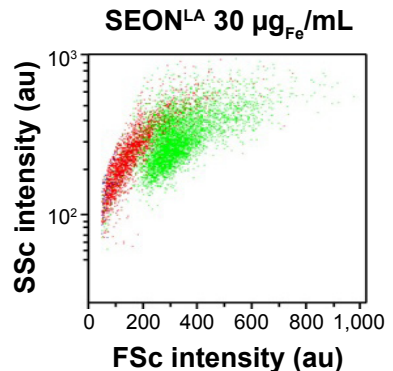
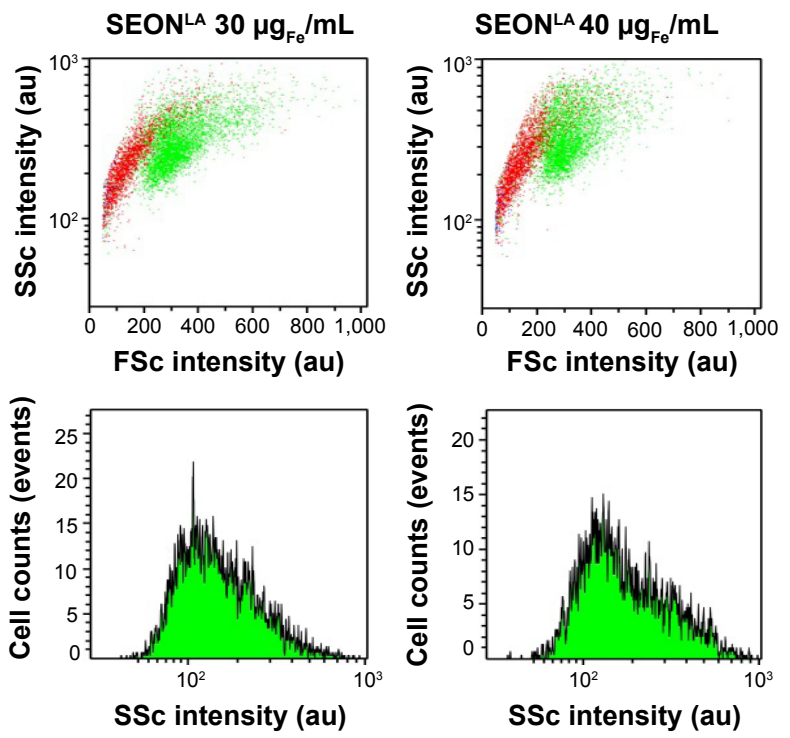

Figure S3 Representative flow cytometry graphs of SSc and FSc. HUVECs were cultured for 48 hours in medium containing 0-100 $\mu_{\mathrm{Fe}} / \mathrm{mL} \mathrm{SPIONs.} \mathrm{SSc} \mathrm{and} \mathrm{FSc} \mathrm{were}$ measured by flow cytometry. Graphs show SSc plotted against FSc, and SSc against the number of counted cells (events).

Notes: (A) Graphs of untreated cells and cells treated with $100 \mu \mathrm{g}_{\mathrm{Fe}} / \mathrm{mL}$ SEON ${ }^{L A}$, SEON ${ }^{L A-B S A}$, and Rienso ${ }^{\circledR}$. (B) Graphs of cells treated with 10, 20, 30, and 40 $\mu \mathrm{g}_{\mathrm{Fe}} / \mathrm{mL}^{2}$ SEON ${ }^{L A}$. The underlying raw data and the data from the AAS measurements were used to determine the correlation between SSC and SPION content.

Abbreviations: au, absorbance units; SSc, side scatter; FSc, forward scatter; SPION, superparamagnetic iron oxide nanoparticle; HUVECs, human umbilical vein endothelial cells; SEON ${ }^{L A}$, lauric acid-coated nanoparticles; SEON LA-BSA, lauric acid/albumin bovine serum hybrid-coated nanoparticles; AAS, atomic adsorption spectroscopy. 
A

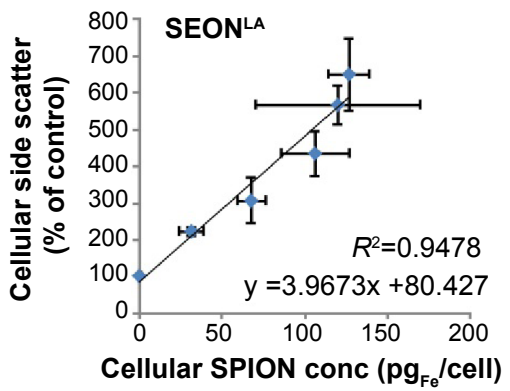

B

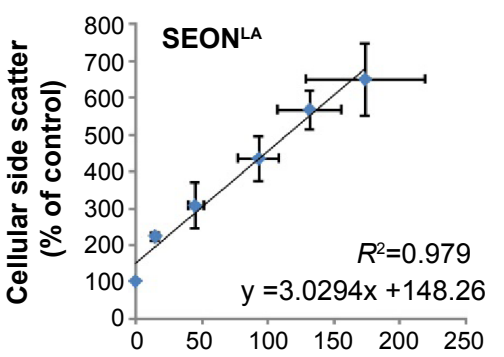

Cellular SPION conc $\left(\mathrm{pg}_{\mathrm{Fe}}\right.$ /cell)
Side scatter versus cellular SPION concentration

uvs

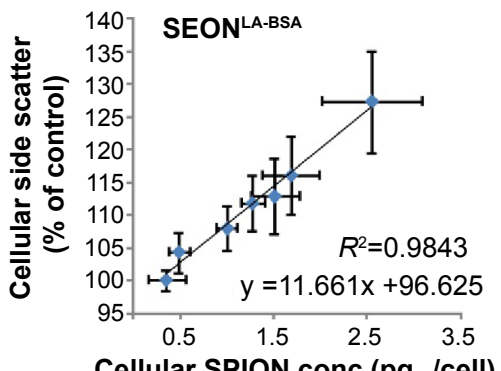

Cellular SPION conc $\left(\mathrm{pg}_{\mathrm{Fe}} /\right.$ cell)

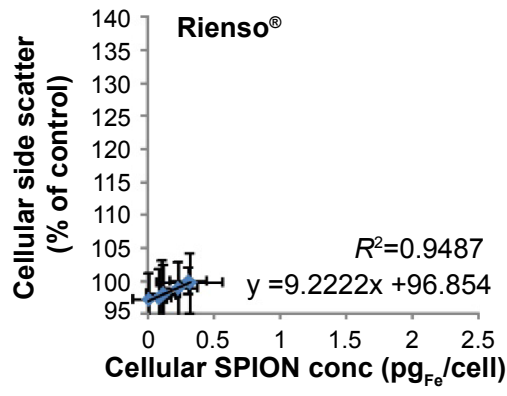

MPS

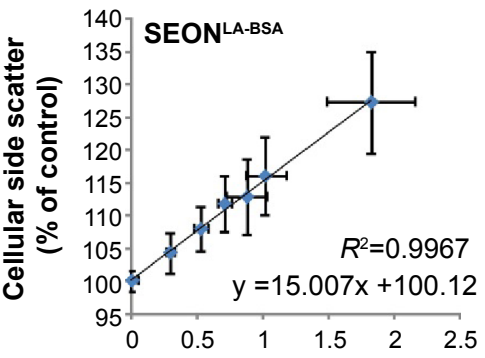

Cellular SPION conc $\left(\mathrm{pg}_{\mathrm{Fe}}\right.$ /cell)

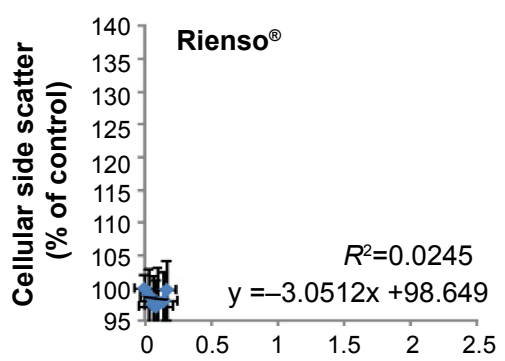

Cellular SPION conc ( $\mathrm{pg}_{\mathrm{Fe}}$ /cell)

Figure S4 Correlation between side scatter measurements and SPION-loads. HUVECs were cultured for 48 hours in medium containing $0-100 \mu \mathrm{g}_{\mathrm{Fe}} / \mathrm{mL}$ SPIONs. Notes: Relationship between the cellular SPION-load as measured by UVS (A) and MPS (B) and the normalized side scatter data delivered by flow cytometry. Results were acquired with SEON ${ }^{L A}$ (left panel), SEON ${ }^{\text {LA-BSA }}$ (middle panel), and Rienso ${ }^{\circledR}$ (right panel). Data are expressed as the mean \pm standard deviation ( $\mathrm{n}=3$ with technical triplicates). $R^{2}$ represents the coefficient of determination. $y$ describes the mathematical relationship between side scatter and cellular SPION content.

Abbreviations: SPION, superparamagnetic iron oxide nanoparticle; HUVECs, human umbilical vein endothelial cells; UVS, ultraviolet spectrophotometry; MPS, magnetic particle spectroscopy; SEON ${ }^{\mathrm{LA}}$, lauric acid-coated nanoparticles; SEON ${ }^{L A-B S A}$, lauric acid/albumin bovine serum hybrid-coated nanoparticles.

\section{Publish your work in this journal}

The International Journal of Nanomedicine is an international, peerreviewed journal focusing on the application of nanotechnology in diagnostics, therapeutics, and drug delivery systems throughou the biomedical field. This journal is indexed on PubMed Central, MedLine, CAS, SciSearch ${ }^{\circledR}$, Current Contents ${ }^{\circledR} /$ Clinical Medicine,
Journal Citation Reports/Science Edition, EMBase, Scopus and the Elsevier Bibliographic databases. The manuscript management system is completely online and includes a very quick and fair peer-review system, which is all easy to use. Visit http://www.dovepress.com/ testimonials.php to read real quotes from published authors. 